\title{
La disolución y liquidación de los consorcios administrativos ${ }^{1}$
}

\section{Dissolution and liquidation of administrative consortia}

\author{
Federico A. Castillo Blanco \\ Universidad de Granada \\ fblanco@ugr.es
}

\begin{abstract}
RESUMEN
El presente estudio analiza las principales novedades introducidas en el régimen jurídico de los consorcios administrativos por las sucesivas reformas acontecidas desde 2013 y que se han plasmado en una regulación básica de éstos que, entre otros temas relevantes, aborda la extinción de los mismos combinando la legislación administrativa y privada. Se analiza la problemática que dicho régimen de extinción plantea poniendo de manifiesto las eventuales soluciones que se pueden adoptar respecto de dicho proceso.
\end{abstract}

\section{PALABRAS CLAVE}

Consorcios, naturaleza, régimen jurídico, resolución, liquidación, responsabilidades, activos, pasivos, deudas.

\begin{abstract}
The present study analyzes the main news introduced in the legal regime of the administrative consortia by the successive reforms that have taken place since 2013 and which have been reflected in a basic regulation of these that, among other relevant issues, addresses the extinction of these by combining administrative legislation and private. We analyze the problems that the extinguishment regime poses by showing the possible solutions that can be adopted with respect to them.
\end{abstract}

\section{KEYWORDS}

Consortia, nature, legal regime, resolution, liquidation, liabilities, passive, debts.

\section{SUMARIO}

I. INTRODUCCIÓN. NATURALEZA JURÍDICA Y RÉGIMEN JURÍDICO GENERAL DE LOS CONSORCIOS PÚBLICOS TRAS LAS ÚLTIMAS REFORMAS ACONTECIDAS. II. LA DISOLUCIÓN DE LOS CONSORCIOS: ¿EVENTUAL RECONDUCCIÓN AL EJERCICIO DEL DERECHO DE SEPARACIÓN? 1. LOS PROBLEMAS DE SUCESIÓN DE NORMAS EN EL TIEMPO: ¿RETROACTIVIDAD O IRRETROACTIVIDAD DE LOS PRECEPTOS DE LA LRJSP? 2. REQUISITOS JURÍDICO-PROCEDIMENTALES PARA LA ADOPCIÓN DE LOS ACUERDOS DE DISOLUCIÓN. 3. EL PROCEDIMIENTO ORDINARIO DE DISOLUCIÓN DE LOS CONSORCIOS. 4. LA NORMATIVA SUPLETORIA: CARACTERÍSTICAS GENERALES DE LA SOCIEDAD CIVIL, CAUSAS DE EXTINCIÓN Y SU APLICACIÓN A LOS CONSORCIOS PÚBLICOS. 5. ¿CABE LA DISOLUCIÓN JUDICIAL O LO PROCEDENTE ES EL EJERCICIO DEL DERECHO DE

1 El presente estudio se realiza en el marco de los trabajos que se desarrollan en Proyecto I+D del Ministerio de Economía y Competitividad "Remodelando el empleo publico y la organización administrativa para garantizar el Estado de Bienestar" (DER 2013-48416-C2-1-R). 
SEPARACIÓN? III. EL PROCEDIMIENTO DE LIQUIDACIÓN DE LOS CONSORCIOS EN LA LRJSP, EN LA LEGISLACIÓN AUTONÓMICA Y EN LA LEGISLACIÓN SOCIETARIA. 1. LAS OPERACIONES PREVIAS A LOS ACTOS DE LIQUIDACIÓN: DETERMINACIÓN DE LOS CRITERIOS A SEGUIR EN ESTA. 2. LA FIGURA DEL LIQUIDADOR EN LOS CONSORCIOS. 3. LA RESPONSABILIDADES EN QUE INCURREN LOS LIQUIDADORES. 4. LAS OPERACIONES JURÍDICAS Y MATERIALES DE LA LIQUIDACIÓN DEL CONSORCIO. 5. ACTIVO Y PASIVO SOBREVENIDO Y RESPONSABILIDAD FRENTE A DEUDAS FUTURAS. IV. LA CESIÓN GLOBAL DE ACTIVOS COMO PROCEDIMIENTO DE EXTINCIÓN DE LOS CONSORCIOS EXISTENTES. V. BIBLIOGRAFIA.

\section{INTRODUCCIÓN:. NATURALEZA JURÍDICA Y RÉGIMEN JURÍDICO GENERAL DE LOS CONSORCIOS PÚBLICOS TRAS LAS ÚLTIMAS REFORMAS ACONTECIDAS}

En lo esencial, y a los efectos que aquí importan, los Consorcios puede ser definidos como organizaciones de cooperación interadministrativa, dotadas de personalidad jurídica, que varias Administraciones públicas de distinto nivel, junto en su caso a organizaciones privadas, pueden constituir con la finalidad de gestionar intereses públicos comunes en el ejercicio de sus respectivas competencias.

En cualquier caso, los Consorcios encontraron, a lo largo de estas décadas, sus manifestaciones más típicas en la gestión común de competencias concurrentes de los entes consorciados, fundamentalmente en materia de servicios públicos (abastecimiento de aguas) o en materias específicas de interés común no atribuidas en concreto a ninguna de las mismas (prestación de servicios culturales por ejemplo). Bien es cierto que su utilización no siempre ha respondido a fines propios y se ha realizado una utilización intensiva de la figura a veces sin clara justificación y, lo que no es un tema menor, con cierta confusión respecto de otras manifestaciones del asociacionismo administrativo como las mancomunidades. Los problemas de nuestra planta local, por su minifundismo, no son ajenos a esta idea, pero no creo que deba confundirse esta cuestión con la razón de ser del consorcio y su inserción en nuestro ordenamiento como un instrumento de cooperación. Los problemas de nuestra planta municipal, y las definitivas soluciones que hayan de darse al espacio supramunicipal, están relacionados con la patología de éste, pero no son la razón de ser del Consorcio y por ello el planteamiento de su regulación, desde este punto de vista como recientemente se ha realizado, no hará sino confundir la óptica desde la que la cuestión ha de ser enfocada.

Su utilización, por lo demás, fue notoriamente más intensiva en el nivel local lo que llevó a la doctrina a calificarlo, en un primer momento, como ente local lo que, desde mi punto de vista y así lo puse de manifiesto en uno de mis primeros trabajos ${ }^{2}$, no podía ser mantenido tras la Ley $7 / 1985$, de 2 de abril, Reguladora de Bases de Régimen Local (en adelante LRBRL) que excluyó a estos de la enumeración de entes locales situándolo, más certeramente, como una entidad derivada del principio de cooperación en el artículo 57 de la LRBRL ${ }^{3}$. En la actualidad, además, en el caso de las entidades locales es un instrumento de cooperación subsidiario de otras fórmulas de cooperación interadministrativa ${ }^{4}$.

2 CASTILLO BLANCO, F. A. (1991): 397 y ss.

3 En efecto, el debate sobre si el Consorcio es o no un ente local y sobre la capacidad del legislador autonómico para crear entidades locales no necesarias o dispositivas es algo ya sabido por conocido. De esta forma, entienden que el artículo 3.2 de la LRBRL es un listado abierto ALONSO MÁS, (2005): págs. 185-187; MARTíN MATEO, (1987): pág. 22; MORILLO-VELARDE (2005): pág. 631; SÁNCHEZ BLANCO, (2006): pág. 87. Muy destacadas en este aspecto son las reflexiones de TOSCANO GIL (2011): pág. 45 para quien la configuración del consorcio local como entidad local por el legislador autonómico es posible ya que «si en la práctica los estatutos reguladores de los consorcios locales suelen configurarlos como entes de Derecho público que gestionan intereses predominantemente locales, entes participados e integrados mayoritariamente por Administraciones Públicas locales, y sujetos fundamentalmente al Derecho local, ningún problema debería haber en dar el siguiente paso, el de definirlos como entes locales en la normativa autonómica».

No es esta mi posición, sin perjuicio de las competencias autonómicas en materia de régimen local (STC 31/2010). Así lo he expuesto en trabajos ya citados más atrás. Tampoco es la de REBOLLO PUIG (1997): pág. 209. La nueva regulación establecida, en un primer momento en la Disposición adicional vigésima de la LRSAL, y la LRJSP recientemente dictada avala más, aun si cabe, esta postura y es que, a la vista de la misma, resulta muy complicado mantener la condición de ente local del Consorcio cuando el régimen jurídico puede variar sustancialmente según el criterio de adscripción del mismo. Lo que indica que estamos frente a un ente instrumental de carácter asociativo que será local o no, o mejor dicho al que le será de aplicación o no la legislación local, dependiendo de su adscripción a una u otra Administración.

4 La STC de 3 de marzo de 2016 considera que dicha característica es plenamente constitucional. De esta forma, razona la Sentencia que: «La preferencia asignada a la fórmula convencional en detrimento de la consorcial (apartado 3 ) puede discutirse políticamente, pero constituye una directriz directamente encaminada a desarrollar una política de contención de personificaciones públicas que se sitúa dentro de los amplios márgenes de configuración legislativa que abre la Constitución y amparan los apartados 14 y 18 del art. 149.1 CE. Lo mismo cabe decir de la previsión de que los consorcios constituidos no podrán demandar más recursos de los inicialmente previstos (apartado 3)». 
De otro lado, y en relación a su naturaleza ${ }^{5}$, el Consorcio administrativo puede caracterizarse como una Corporación de naturaleza mixta ${ }^{6}$, instrumental y asociativa, de Derecho público que se distingue de otros instrumentos de cooperación administrativa por la presencia de tres elementos esenciales, a saber: una composición de distinto nivel interadministrativa, la existencia de una finalidad específica y común a las entidades que la conforman y la necesaria existencia de personalidad jurídica que se plasma en una organización del mismo con órganos unipersonales y colegiados. Esta cuestión, sin embargo, no ha sido pacífica y el debate sobre su naturaleza no es nuevo y sobre el mismo se ha escrito suficiente aunque me temo que vamos a tener que seguir insistiendo en ella dada la nueva regulación contenida en la Ley 40/2015, de 1 de octubre, de Régimen Jurídico del Sector Público (en adelante LRJSP) y su decantación por su carácter instrumental en detrimento del asociativo ${ }^{7}$.

Lo cierto es que, a pesar de la importante función a desarrollar por los Consorcios derivada de este esencial principio constitucional de cooperación informador de nuestro marco constitucional, éstos han debido desarrollar sus funciones en medio de un notable vacío normativo respecto de los mismos que ha provocado que, tanto en el procedimiento para su constitución, como en los aspectos relativos a la gestión ordinaria de sus actividades (particularmente en el ámbito del control presupuestario y de la gestión del personal) ${ }^{8}$, hayan surgido numerosos conflictos derivados, fundamentalmente, de la indeterminación de la naturaleza jurídica de esta figura y de la imprecisión de sus propios Estatutos? ${ }^{9}$.

5 Cuestión a la que nunca ha sido ajena nuestra doctrina. Puede verse, a este respecto, MARTíNEZ LÓPEZ-MUÑIZ (1974) y MARTÍN MATEO, R. (1971): 9 y ss. CASTILLO BLANCO, F. A. (1991): 397 y ss. Más recientemente cabe citar los trabajos de MARTíN MATEO (1987) y MARTÍN MATEO (1992): 8 y ss.; LÓPEZ MENUDO, F. (1995); CASTILLO BLANCO, F. A. (2001): 95 y ss; NIETO GARRIDO, E. (1997); BARRERO DOMÍNGUEZ, C. (2002): 81 y ss. y REBOLLO PUIG, M. (1997). Más recientemente TOSCANO GIL, F. (2011).

6 Explica muy bien dicha naturaleza, que podríamos calificar de mixta, TOSCANO GIL (2015), cuando expone que «Un consorcio administrativo es una Administración Pública instrumental de base asociativa. Como Administración Pública es un ente dotado de personalidad jurídico-pública, que ejerce potestades administrativas y se rige por el Derecho Administrativo. En tanto entidad instrumental de base asociativa, el consorcio se caracteriza por depender de un ente matriz, en realidad una pluralidad de entes matrices, en la medida en que lo integran, asociándose para ello, diversas Administraciones Públicas, e incluso, en su caso, entidades privadas sin ánimo de lucro en identidad de fines con las Administraciones con las que se asocian. De lo que resulta que esta base asociativa puede calificarse de heterogénea, en cuanto las Administraciones que lo componen no tienen que ser necesariamente del mismo tipo10, además de admitir en su seno, como se acaba de decir, entidades que no son Administraciones Públicas. A su vez, la naturaleza asociativa del consorcio implica su voluntariedad, siendo así que las entidades que lo integran lo hacen voluntariamente, no porque se les imponga desde un nivel de gobierno superior.

Esta base asociativa lo diferencia de otras entidades instrumentales públicas, como los organismos autónomos, mientras que la heterogeneidad en su composición lo distingue de otras fórmulas asociativas de naturaleza jurídico-pública, como la mancomunidad de municipios 11, siendo dicha personalidad jurídico-pública lo que lo separa de otras formas de gestión compartida, como las sociedades mercantiles participadas por diversas Administraciones Públicas, que ni pueden ejercer potestades públicas ni se rigen por el Derecho Administrativo».

7 Es unánime la crítica a dicha previsión y, por todos, cabe citar aquí a, entre otros, a TOSCANO, NIETO GARRIDO y quien escribe estas líneas. Véase, respecto de dicha consideración, CASTILLO BLANCO, F. (2014). Más recientemente puede verse, asimismo, el trabajo del mismo autor "La incidencia de la nueva Ley de Régimen Jurídico del Sector Público en los instrumentos de cooperación del Estado Autonómico: especial referencia a los consorcios públicos", Diario de Derecho Municipal, IUSTEL, Edición de 10/03/2017.

En este sentido, se había mantenido que el artículo 110.4 TRRL que recordemos que prevé que los «órganos de decisión» del consorcio «estarán integrados por representantes de todas las Entidades consorciadas, en la proporción que se fije en los Estatutos respectivos» podría conciliarse con esta previsión, pero su derogación expresa en la LRJSP veta dicha consideración.

Si cierto era, inclusive con anterioridad a las últimas reformas, su naturaleza instrumental antes de que esta Ley con su regulación lo estableciera tan clara y decisivamente, no lo es menos que también es un ente asociativo del que forman parte varias Administraciones públicas y que, en el adecuado equilibrio, entre esas dos características radicará el éxito de la figura dada su vocación y finalidad. Ciertamente puede haber conflicto con alguna normativa autonómica, como ha puesto de relieve algún autor, pero en mi opinión el problema va más allá y es que el interés en la participación de otras entidades inclusive del mismo nivel, distinta a la de adscripción, será muy reducido cuando no inexistente si su papel resulta excesivamente reducido. Se trata de intereses comunes a resolver, por una institución común, que ha de responder a dichas características. Me temo que, sin embargo, dicho aspecto no se ha cuidado excesivamente. A título de ejemplo, y en el caso de los Consorcios adscritos entes locales, la determinación por parte de la entidad local a la que ha resultado adscrito el Consorcio del número de miembros del órgano de gobierno del Consorcio con independencia de la voluntad del resto de los miembros del Consorcio lo que parece absolutamente carente de sentido común en una Administración que, ciertamente es instrumental -siempre lo ha sido-, pero no de una Administración en exclusiva sino de varias. ( $¿$ ?)

8 Como es conocido no será hasta la aprobación de la LRJPAC sino cuando se reconozca, por primera vez en el ámbito estatal, y al margen de la legislación de régimen local, la figura del consorcio interadministrativo.

Inicialmente en su artículo 7, y, tras la reforma operada por la Ley 4/1999, de 13 de enero, en su artículo 6.5, la LRJPAC reconoció a los consorcios como una manifestación del principio de colaboración interadministrativa con lo que su naturaleza como ente local se ponía definitivamente en entredicho.

9 FERREIRA FERNÁNDEZ (2009), cita como un ejemplo de esta incertidumbre y confusión en el caso gallego dos resoluciones jurisdiccionales en el mismo Juzgado (JCA n. 2 de Santiago de Compostela), con dos pronunciamientos absolutamente contradictorios 
En el ámbito local, además y como característica singular de éstos, podían formar parte de los consorcios entidades privadas sin ánimo de lucro que persiguiesen fines públicos concurrentes con los de las Administraciones públicas. Hasta ahora sin ánimo de lucro, bien es cierto que este último aserto ha sido objeto recientemente de modificación y, a partir de la entrada las últimas reformas normativas, el artículo 118 LRJSP prescribe, con carácter básico, que los mismos pueden estar conformados también por entidades privadas tengan o no ánimo de lucro.

Tras la regulación ofrecida por la Ley de Racionalización y Sostenibilidad de la Administración Local aprobada a finales de 2013 (en adelante LRSAL), que ha incidido singularmente en el régimen jurídico de los Consorcios públicos, especialmente en aquellos adscritos a un ente local, la regulación de carácter básico que ofrecen los mismos es, y sin perjuicio de que compartamos o no determinadas soluciones, mucho más acabada. Regulación que ha sido completada con las novedades aportadas en la materia objeto de estudio en este trabajo que, a este respecto, ofreció la Ley 15/2014, de 16 de septiembre, de Racionalización del Sector Público y otras medidas de reforma administrativa (en adelante LRSP) y por la definitiva regulación que ha ofrecido la Ley 40/2015, de 1 de octubre, de Régimen Jurídico del Sector Público (en adelante LRJSP) que, sin embargo, y en lo que se refiere al espacio local no procede a derogar múltiples preceptos introducidos en la LRBRL en la reforma acontecida en 2013 que son aplicables en exclusiva a los consorcios locales y que habían sido dictados, más bajo una óptica casi estrictamente presupuestaria, que con una visión de largo alcance respecto de la misión de estas entidades públicas ${ }^{10}$.

Sin embargo, y al menos desde mi punto de vista y sigo insistiendo en ello, la figura consorcial exigiría una regulación acabada de carácter básico aplicable a todo tipo de consorcios que estableciera los elementos claves de la figura en cuanto a su constitución, organización, funcionamiento y extinción, sin perjuicio de las competencias autonómicas para su desarrollo y sin necesidad de esas singularidades establecidas en la legislación básica de régimen local que, como se ha expuesto, tan solo encuentran alguna explicación en el momento de crisis económica en que fueron dictadas.

En concreto, y respecto del régimen jurídico aplicable a los Consorcios, cabe referirnos, en primer término, al carácter de la normativa contenida en la LRJSP. Y es que dicha normativa, en cuanto régimen jurídico básico, es de aplicación a todas las Administraciones Públicas y está dictada de conformidad con tres títulos constitucionales muy concretos que explican, por su invocación, el alcance y objetivos de la regulación efectuada (DF 14), a saber: los arts. 149.1.18 relativo a las bases del régimen jurídico de las Administraciones Públicas, el apartado 13 de ese mismo artículo referido a la coordinación de la planificación general de la actividad económica y el apartado 14 relativo a la Hacienda Pública general. No resulta sorpresivo los títulos utilizados, dada la regulación efectuada, y atendiendo al momento en que la misma se dicta. Otra cosa será que sea acertado si miramos la problemática con una cierta perspectiva más allá de la situación económicofinanciera que aún vivimos ${ }^{11}$.

Hemos aludido a que la regulación es básica, pero, ciertamente, no toda la regulación tiene ese carácter (DF 14): no la tiene, a título de ejemplo, el artículo 123.2 que se circunscribe tan solo al Estado cuando va a proceder a la creación de un Consorcio; tampoco la tiene la DA 4. ${ }^{a}$ (plazo adaptación Sector Público Estatal),

sobre la naturaleza jurídica del Consorcio Gallego de Servicios de Igualdad y Bienestar. Nótese que es el mismo órgano jurisdiccional, el que en dos sentencias coincidentes en el tiempo (7 de mayo y 30 de julio de 2007), y ante supuestos de hecho idénticos, concluye, en uno y otro proceso, respectivamente, en la naturaleza jurídica autonómica y local del referido ente consorcial.

10 De similar opinión es NIETO GARRIDO, E., (2016): págs. 2.115-2.116 quien, con acierto, señala además que la institución del consorcio administrativo ha sufrido en los últimos tres años una revolución en cuanto a las normas que lo regulan que han supuesto un cambio de paradigma sin precedentes.

11 Los prejuicios del legislador los ha puesto de relieve, en referencia a la LRSAL, TOSCANO GIL (2015), que expone que «las medidas adoptadas por la LERSAL son especialmente gravosas para el consorcio, por razón de las importantes limitaciones que establece para la constitución y mantenimiento de los mismos, reduciendo en gran medida la flexibilidad que ha sido seña de identidad de esta figura. Cuando se presenta políticamente el proyecto de reforma, y se anuncia el propósito de reducir el número de consorcios existentes, se hace denunciando su elevado número, y acusando su mal funcionamiento. Lo primero será cierto, no lo negamos, pero es cuestionable que sea un problema en sí mismo, puesto que la elevada utilización de una herramienta jurídica no es en principio una prueba de su fracaso, sino más bien de su éxito. Otra cosa es que su elevado uso se tache de ineficiente, o de insostenible, en atención a los fines que se persiguen. Y entonces ya, sí, hablemos de lo segundo, consorcios que funcionan mal. Pero no partiendo de un prejuicio acerca de su funcionamiento, que bien puede evidenciar el desconocimiento y la ignorancia acerca de esta figura, y carecer de fundamento empírico alguno, o de una valoración detenida y meditada sobre lo que de bueno y lo que de malo tiene el consorcio. Esta premisa, claro está, obliga a discriminar a la hora de adoptar estas medidas, desde esta perspectiva, la de la sostenibilidad financiera y la eficiencia, que es la que finalmente adopta la Ley, algo más cuidadosa en su redacción final que en los primeros borradores normativos, en los que el consorcio parecía haberse convertido, junto con las mancomunidades y las entidades locales menores, en uno de los enemigos a batir». 
ni la DT 2 (transitoria relativa a dicha adaptación), ni el ap.2 DF 17 (adaptación normativa consorcios creados por ley Cortes Generales).

Pero, además, y para completar dicha visión sobre la normativa aplicable, a la regulación establecida en los arts. 118-127, hay que añadir la establecida, también con carácter básico, en los arts. 81-83 que se aplican a todo el Sector Público Institucional, la DA 8. ${ }^{a}$ (plazo inscripción Inventario), la DA 10. ${ }^{a}$ (aportaciones a los Consorcios) y el ap.1 DF 17. ${ }^{\text {a }}$ (adaptación de normativa estatal y autonómica a la regulación establecida).

Todo ello conduce a que hagamos referencia a las fuentes de su régimen jurídico. Pues bien, el artículo 119 deja claramente establecido el orden de prelación de las fuentes relativo a su régimen jurídico (apartados 1 y 2) estableciendo el carácter supletorio de las normas contenidas en la legislación de régimen local. En conclusión, y la vista de dicho precepto, el régimen de las fuentes será el siguiente según la norma:

a) Lo dispuesto en la LRJSP, la normativa autonómica de desarrollo general o de régimen local, y, por último, lo dispuesto en sus Estatutos (art. 119.1) ${ }^{12}$.

b) Supletoriedad del Código Civil (sociedad civil) para separación, disolución, liquidación y extinción (artículo 119.2), salvo la liquidación que se regirá por lo dispuesto en el art. 97 LRJSP y RD Legislativo $1 / 2010$, de 2 de julio.

Es relevante destacar, a la vista de lo dispuesto, la declaración de supletoriedad de la normas previstas en la legislación local (articulo 119.3) ${ }^{13}$. Más específicamente las que se contienen en la LBRL (art. 26, 57, DA 9. ${ }^{a}$ y $12 .{ }^{a}$ ) y en la LRSAL (DA 13. ${ }^{a}$ y $14 .^{a}$ ). A mi juicio, ya he hecho referencia a ello, no es lo más acertado.

En suma, y sin perjuicio del desarrollo que más adelante realizaremos específicamente respecto de su disolución y liquidación, los Consorcios se regirán, con carácter general y respetando lo establecido legalmente con carácter básico por las normas referidas ${ }^{14}$, por sus propios Estatutos, los cuales determinarán sus fines, así como su régimen orgánico, funcional y financiero.

\section{LA DISOLUCIÓN DE LOS CONSORCIOS: ¿EVENTUAL RECONDUCCIÓN AL EJERCICIO DEL DERECHO DE SEPARACIÓN?}

\section{Los problemas de sucesión de normas en el tiempo: ¿retroactividad o irretroactividad de los preceptos de la LRJSP?}

Parece conveniente, y antes de analizar el régimen jurídico vigente, que nos preguntemos por la normativa aplicable a la disolución y liquidación de los Consorcios Públicos dado que en un breve plazo de tiempo dos normas, al menos, han venido a regular ésta.

Cabe señalar, en primer término, que desde mi punto de vista la fecha del acuerdo de disolución va a marcar las normas de aplicación al procedimiento que serán las vigentes en el momento en que se adoptase el mismo pues este, aunque no haya producido la extinción de la personalidad jurídica, ha producido plenamente sus efectos propios conduciendo a dicho organismo a cesar en sus relaciones entre los miembros y con terceros y quedar sin actividad alguna, sin perjuicio de la formalización de las operaciones de liquidación ${ }^{15}$.

12 NIETO GARRIDO, E. (2016), "El nuevo marco jurídico del sector público. a propósito de la ley 40/2015, de 1 de octubre, de régimen jurídico del sector público", El Derecho (edición 9-XII-2016) estima, sin embargo, que la disposición derogatoria única del proyecto de ley que deroga los art.87 LBRL y 110 TRRL ha dado carpetazo a la tradicional concepción del consorcio administrativo como ente de constitución voluntaria regido por unos estatutos que eran la ley del consorcio. No es mi opinión que, sin perjuicio de admitir como no puede ser de otra forma, esa derogación no creo que su significado se traduzca necesariamente en una conclusión tan absoluta. De hecho estimo que éstos son una ventana de oportunidad para paliar algunos desaciertos de la normativa dictada.

13 Dicha solución es calificada por GARCÍA RUBIO, (2015), como algo inaudito y novedoso generando unas normas básicas de diferente prelación en rango legal.

14 De ineludible cita resulta en este punto, por el excelente análisis que realiza, el reciente trabajo de BARRERO RODRÍGUEZ, C. (2016)

15 La adopción del acuerdo de disolución por el órgano competente del consorcio motiva su pase de situación «con actividad» a la de «sin actividad», por aplicación de la reglas de la Instrucción de Contabilidad, tanto autonómicas como es el caso de Andalucía (Tercera parte. Cuentas Anuales), como local (regla 4) que determinan que en los casos de disolución las cuentas anuales se refieran al período que va desde el 1 de enero hasta la fecha de disolución. En estos supuestos, por tanto, y adoptado el acuerdo de disolución las cuentas anuales solo deberán ser rendidas respecto del período referido. 
Pues bien, en una primera conclusión, las previsiones contenidas en la LRJSP, regirán a partir del 2 de octubre de 2016 (y lo mismo podría decirse respecto de la normas sobre disolución y liquidación previstas en la norma de 2014 a partir de 18 de marzo de 2015), y, con ello, serán plenamente aplicables a los procedimientos de disolución y liquidación de los Consorcios que no hayan iniciado los mismos (sea cuales sean las previsiones estatutarias establecidas inclusive en supuestos de no adaptación estatutaria pues dichas normas serán aplicables exlege).

Pero la situación pudiera ser más compleja ya que, como ha acontecido en algunos supuestos, dichos procedimientos de extinción se han iniciado en muchos casos, o con anterioridad a dichas normas o en el interregno de las mismas, por lo que se plantea cual sea la norma de aplicación. A estos efectos, y siguiendo el criterio de que el acuerdo de disolución resulta esencial a estos efectos, a nuestro juicio se pueden distinguir varias situaciones:

\section{A) No adopción de acuerdo de disolución a la fecha de entrada en vigor de la LRJSP (igual conclusión habría que llegar con relación a la entrada en vigor de la Ley 15/2014)}

En mi opinión se regirán plenamente por lo dispuesto en la LRJSP, y el resto de normativa aplicable incluidos los Estatutos, tanto en lo que se refiere a la disolución como a la liquidación.

\section{B) Adopción del acuerdo de disolución pero no publicación del mismo}

En estos supuestos, aunque discutible jurídicamente dado que se trata de un ejercicio de ponderación de bienes jurídicos en relación muy específicamente con la seguridad jurídica ${ }^{16}$, podría seguirse el criterio establecido en el artículo 2.3 Cc. y publicado éste que la liquidación se rigiese por los criterios de la legislación en vigor a la fecha de la adopción del acuerdo de disolución del Consorcio.

Avalarían dicha conclusión las propias normas reguladoras vigentes ${ }^{17}$ :

Pero ¿qué sucede en aquellos Consorcios que no han declarado dicha situación? ¿Basta la inactividad de éstos para entender que, desde el momento que se produce, no existirían dichas obligaciones?

Desde mi punto de vista no es posible acoger dicha tesis. Ya se aplique la normativa civil (si se entendiera que ha concluido su objeto) o mercantil (que contempla específicamente la inactividad de los órganos sociales) es precisa la constatación de la causa de disolución por el órgano máximo rector del Consorcio. En estos supuestos, en principio, y salvo datos adicionales, sería preciso, por tanto, entender prorrogados los presupuestos, liquidar los ejercicios presupuestarios y rendir las pertinentes cuentas generales.

En el ámbito mercantil se discute la eficacia declarativa o constitutiva de dicho acuerdo lo que incidiría, de forma decisiva, sobre esta cuestión. Hemos de poner de manifiesto que, tras la promulgación del régimen vigente en materia de sociedades de capital, resulta mayoritariamente aceptado doctrinalmente que la disolución se produce a partir del acuerdo social o de la sentencia. Lo expuesto no resulta contradicho porque se reconozca que la aparición de la causa de disolución suponga el inicio del procedimiento disolutorio, siendo aquí donde reside su trascendencia. Las discrepancias se centran fundamentalmente a la hora de precisar cuál es el contenido del acuerdo o de la decisión judicial. Para los partidarios de la eficacia declarativa la junta general o el juez se limitan a emitir una declaración de ciencia. Por su lado, predicar la eficacia constitutiva implica dotar a la disolución de una estructura compleja: junto al motivo disolutorio ha de concurrir un acuerdo social o una sentencia judicial.

A nuestro juicio, y en el caso de los Consorcios, el acuerdo del máximo órgano rector tendría eficacia constitutiva. En efecto, la idea central que subyace en los procedimientos de disolución en que acontece una causa para ello es que la sociedad (en nuestro caso el Consorcio respectivo), una vez acaecida la causa, ha de decidir sobre su continuidad. La sociedad no puede continuar ejerciendo su actividad en las condiciones concurrentes, pues así lo ha prescrito el legislador (causas obligatorias) o lo acordaron los socios (causas estatutarias). Por esta razón, se inicia el procedimiento disolutorio cuya pieza principal es la convocatoria del máximo órgano rector del Consorcio donde los miembros de éste deben decidir sobre el futuro de la entidad. Y es, a partir de ese momento, donde se aplicaría lo ya visto con anterioridad y previsto en las normas contables.

Y dicha conclusión se ve avalada por la regulación que, del ejercicio de derecho de separación, al que más adelante aludiremos, realizan tanto la LRSP como la LRJSP que expresamente establecen:

La efectiva separación del consorcio se producirá una vez determinada la cuota de separación, en el supuesto en que ésta resulte positiva, o una vez se haya pagado la deuda, si la cuota es negativa.

Luego, y por tanto y en nuestra opinión, es preciso el acuerdo del máximo órgano del Consorcio y no basta la mera declaración de voluntad de la Administración a la que está adscrito éste (artículo 13.2 y 126.2 respectivamente).

16 A título de ejemplo podemos ver como, en ocasiones, se considera de aplicación la nueva norma en ese ejercicio de ponderación. De esta forma, y a propósito de una Sentencia del Tribunal Supremo en materia concursal, la que se dicta en fecha 4 de septiembre de 2014, este no dudará en establecer:

«Examinadas las alegaciones de las partes en relación con los arts. 2.3 CC, 9.3 CE y Disposiciones transitorias del CC (?), el criterio de la Sala es el de aplicación íntegra de la normativa de la nueva Ley Concursal».

17 Es preciso hacer referencia a que, en el caso andaluz, la LAULA, por expresa remisión de su artículo 82 al artículo 77 que versa sobre la disolución de mancomunidades, condiciona a la publicación de ésta la extinción de la mancomunidad y es, por tanto, condición ineludible para que desaparezca de la esfera jurídica quedando, mientras tanto, en la situación de «sin actividad», criterio 
- Por un lado, el propio artículo 14 de la LRSP y el artículo 127 LRJSP que establecen que la disolución del consorcio produce su liquidación y extinción. Es decir, estas segundas fases no son sino efectos del acuerdo de disolución que es el determinante para la finalización de la vida jurídica del Consorcio que queda en situación de «sin actividad» hasta que finalicen dichas operaciones materiales.

- Por otro, el artículo 371 del Real Decreto Legislativo 1/2010, de 2 de julio, por el que se aprueba el Texto Refundido de la Ley de Sociedades de Capital reitera que la disolución de la sociedad abre el período de liquidación. De esta forma, aunque conserve personalidad jurídica, la sociedad -en nuestro caso el Consorcio- no puede adoptar acuerdo alguno salvo la de aprobación de la liquidación consistente en un conjunto de operaciones materiales y jurídicas derivadas de los criterios establecidos en la disolución.

Por último, y en esa misma línea, los Estatutos de los Consorcios suelen recoger fórmulas que hacen de la fecha del acuerdo de disolución la determinante para dirimir la legislación de aplicación pues normalmente en éste se contempla la forma en que haya de procederse para la liquidación del Consorcio y, en este supuesto solo de forma supletoria, regirán las reglas establecidas en la legislación societaria que, sin embargo, pueden inspirar dicho acuerdo.

\section{C) Adopción del acuerdo de disolución y publicación del mismo}

En este último supuesto habría que inclinarse por la normativa vigente en la fecha del acuerdo de disolución ya que la liquidación (que no consiste sino en operaciones materiales y jurídicas derivadas del acuerdo de disolución), como hemos explicitado, se produce por la disolución: en este sentido, por la normativa anterior a 2014 cuando aún habiéndose producido en dicho ejercicio -o en ejercicios anteriores- se haya producido con anterioridad al 18 de marzo de 2015 (fecha de entrada en vigor de la LRSP con el periodo transitorio de seis meses previsto en la norma), por la LRSP a partir de la entrada en vigor de esta norma y del plazo transitorio de seis meses previsto en la norma para la adaptación estatutaria y hasta 2 de octubre de 2016 que entrará en vigor la LRJSP y, por tanto, sería de plena aplicación en estos supuestos.

\section{Requisitos jurídico-procedimentales para la adopción de los acuerdos de disolución}

Ha de destacarse el papel esencial que juegan en esta materia los Estatutos del Consorcio. De esta forma, los Estatutos de los consorcios han de determinar la Administración pública de adscripción, las entidades que vayan a integrarlo, su régimen orgánico, funcional y financiero de conformidad al régimen jurídico de la administración matriz.

La no adaptación de los Estatutos a las previsiones legales, por otro lado, tampoco merma, como se ha explicado doctrinalmente ${ }^{18}$, que sea de aplicación exlege la normativa de la Administración a la que esté adscrito por disposición de la Ley el Consorcio.

\footnotetext{
distinto a aquellos supuestos a los que sea de aplicación la LRJSP que, en su artículo 97.4, condiciona la extinción a la formalización de la liquidación y no al acuerdo de disolución. Pero dichas previsiones no necesariamente han de motivar un cambio de opinión. En un caso porque es de aplicación a los Consorcios locales y, en el otro, porque una cosa es que la extinción se produzca con la formalización de la extinción y otra, muy distinta, es que legislación haya de ser de aplicación a la liquidación.

18 Vid. CASTILLO BLANCO, F. (2014). En efecto la pregunta a resolver es ¿Es necesaria la adaptación estatutaria? Puede decirse que sí hay algunos mandatos de desarrollo normativo en el sector público estatal cuando el consorcio está adscrito a este, pero no se aclara que acontece en el sector autonómico y local que, aún quedando diferido a la adaptación normativa que se haga en el ámbito autonómico, no hace inaplicable a la norma estatal.

El caso, sin embargo, que se plantea es ¿Qué acontece si los Estatutos del Consorcio no han sido adaptados antes de la entrada en vigor de dichas normas?.

En realidad, los Consorcios se rigen por sus propios Estatutos hasta el momento en que estos no se adapten a las previsiones establecidas según lo dispuesto en las normas transitorias ya citadas. Para evitar demoras injustificadas, se previó en la LRSAL una disposición transitoria sexta que establecía un plazo máximo de un año para esa adaptación (31 de diciembre de 2014 ; fecha a partir de la cual se aplicarían, en su defecto, íntegramente las previsiones de la Ley). A esa regla transitoria se le añadía otra más: cuando esa adaptación requiriera un cambio de régimen jurídico del personal, en el régimen presupuestario, contable o de control, este nuevo régimen sería de aplicación a partir del 1 de enero del año siguiente.
} 
En este sentido, el régimen de las fuentes, a estos efectos, viene definido según expusimos por la siguiente jerarquía producida exlege la adscripción de dichos Consorcios a la Administración que corresponda según los criterios establecidos para ello ${ }^{19}$ :

a) $1 .{ }^{\circ}$ La legislación básica estatal (LRJSP), 2. ${ }^{a}$ normativa autonómica de desarrollo ${ }^{20}$, y $3 .^{a}{ }^{\text {Estatutos }}$ (art. 119.1).

b) Supletoriedad del CC (sociedad civil) para separación, disolución, liquidación y extinción, salvo liquidación: art. 97 LRJSP y RD Legislativo 1/2010.

c) Supletoriedad para los consorcios locales de la LRBRL (art. 57, DA 9. y $12 .^{a}$ ) y Ley $27 / 2013$ (DA $13 .{ }^{a}$ y $\left.14 .^{a}\right)^{21}$ :

La regla era clara y su sentido también: las adaptaciones estatutarias se habían de producir antes de un año desde la entrada en vigor de la ley, sus efectos aplicativos sobre el personal, régimen presupuestario, contable o de control (por razones obvias de ajuste al ciclo presupuestario), a partir del 1 de enero de 2015. A esa adaptación estatutaria, en algunos casos compleja desde el punto de vista material y procedimental, se le debería haber sumado las previsiones establecidas en la Ley de racionalización del sector público y de medidas de reforma administrativa sobre todo si, como acontece, no presenta una problemática especial y aclaraba el régimen jurídico de éstos en los casos de disolución y liquidación de los mismos.

De lo que no hay duda es que dicho plazo es de carácter preceptivo.. ¿Pero que sucede si se incumplen? Pues bien, y aunque pueda resultar paradójico, no se establece sanción ni consecuencia alguna para el incumplimiento de dicho plazo y, en consecuencia, debemos considerar dicho plazo como una irregularidad que no produce efecto alguno de invalidez. Por tanto el plazo, aunque preceptivo, no es de carácter esencial y, por tanto, su incumplimiento no tendrá consecuencia más allá de la inseguridad jurídica que produce la aplicación de la legislación vigente con unos Estatutos que han quedado modificados exlege, pero no adaptados a ésta, verbigracia: se adapten o no los Estatutos el Consorcio quedará adscrito a la Administración pública que corresponda, los miembros del mismo podrán ejercitar su derecho de salida en las condiciones legalmente establecidas, etc. y les será de aplicación la legislación de la Administración Pública a la que quede adscrito y, por tanto, las previsiones establecidas en la legislación de aplicación.

Con anterioridad a dichas fechas (1 de enero y 18 de marzo de 2015) será de plena aplicación la normativa vigente en ese momento respecto del derecho de separación, disolución y liquidación de los Consorcios públicos que, por ejemplo en el caso de Andalucía, y en el caso de los Consorcios sujetos a la legislación local, será la legislación local representada en este punto muy específicamente por la Ley de Autonomía Local de Andalucía y lo dispuesto en esta en lo que se refiere al ejercicio de estos derechos en el caso de los Consorcios y Mancomunidades a cuyo régimen se remite.

19 Teniendo en cuenta la naturaleza de ente de derecho público del consorcio interadministrativo, su sometimiento al derecho público es un requisito que permanece inalterable, sea cual fuere su naturaleza jurídica. No así su sujeción a la legislación local, autonómica o estatal.

En consecuencia, el régimen derivado de la normativa administrativa general resulta íntegramente aplicable a la totalidad de consorcios interadministrativos; así, el régimen jurídico, procedimiento administrativo, normativa básica reguladora del empleo público, contratación administrativa, el patrimonio de las respectivas Administraciones Públicas, la formación de los presupuestos, etc.

La normativa administrativa que determina el régimen jurídico del consorcio dependerá de la Administración de adscripción, resultando según los casos la aplicación de la legislación de régimen local, de la legislación autonómica o de la legislación estatal. La legislación aplicable regula el régimen jurídico primario, encomendando a los estatutos del consorcio la regulación de sus «particularidades» es decir, su régimen orgánico y funcional, dentro de los límites establecidos por la normativa estatal, autonómica o local que le sea de aplicación. Quiere decirse que las posibles lagunas que se produzcan en sus estatutos serán salvadas, según los casos, por la LRJPAC (Ley 39/2015 a partir de 2 de octubre), por la legislación de régimen local general -LRBRL, TRRL y LAULA-, o por la legislación de cada Comunidad Autónoma aplicable.

La ley encomienda la regulación a los Estatutos de las «particularidades» de su régimen jurídico por lo que no se les otorga la facultad de crear un régimen propio para los consorcios distinto al de la administración al que se adscribe ya que sólo se le autoriza a introducir particularidades en dicho régimen pero no excepciones al régimen general. Aún así los Estatutos del consorcio conforman la norma básica del mismo por lo que cada consorcio será diferente encontrándonos tanto tipo de consorcios como estatutos existan.

Sin embargo, el alcance de la adscripción de un consorcio al ente público dominante según los criterios establecidos por la legislación básica, por su composición heterogénea, no puede tener la misma intensidad que el resto de entes instrumentales respecto de la administración matriz (Agencias u Organismos Autónomos). Es por ello que, en estos concretos aspectos, los Estatutos del consorcio jugarán un papel fundamental a la hora de determinar las particularidades que, respecto de la normativa marco de general aplicación en el ámbito del sector público autonómico, presentarán los consorcios en los aspectos organizativos, funcionales y financieros.

20 En el caso de Andalucía, a título de ejemplo, la legislación de la Administración autonómica vendría definida por los artículos 88 y ss de la LAJA o por la LAULA en el caso de que se tratase de Consorcios Locales a partir de marzo de 2015.

21 No obstante es de señalar en este punto el Acuerdo de la Subcomisión de Seguimiento Normativo, Prevención y Solución de Controversias de la Comisión Bilateral de Cooperación Administración General del Estado-Comunidad Autónoma de Andalucía, en relación con la Ley 15/2014, de 16 de septiembre, de racionalización del sector público y otras medidas de reforma administrativa, que establece lo siguiente:

La Comisión Bilateral de Cooperación Administración General del Estado-Comunidad Autónoma de Andalucía ha adoptado el siguiente acuerdo:

$1^{\circ}$. De conformidad con las negociaciones celebradas por el Grupo de Trabajo constituido en cumplimiento del Acuerdo de la Comisión Bilateral de Cooperación Administración del Estado-Administración de la Comunidad Autónoma de Andalucía de 4 de diciembre de 2014, para el estudio y propuesta de solución de las discrepancias competenciales manifestadas en relación con la Ley 15/2014, de 16 de septiembre, de racionalización del sector público y otras medidas de reforma administrativa, ambas partes las consideran parcialmente solventadas en base al siguiente compromiso: 
En cuanto a la legislación básica estatal vendría establecida por los artículos 15 a 18 de la Ley 39/2015, de 1 de octubre, del Procedimiento Administrativo Común de las Administraciones Públicas (a partir de 2 de octubre de 2016).

Si bien, y como también se ha de apuntar, las «particularidades» en este punto vienen definidas estatutariamente siempre que no sean contrarias a las normas antes citadas. Dichas «particularidades», y su remisión a las mismas, se refuerzan según lo previsto en la propia legislación básica estatal y autonómica. De esta forma, las norma básica estatal prevé en el artículo 15.2 de la LPAC de 2015 que: «Los órganos colegiados de las distintas Administraciones Públicas en que participen organizaciones representativas de intereses sociales, así como aquellos compuestos por representaciones de distintas Administraciones Públicas, cuenten o no con participación de organizaciones representativas de intereses sociales, podrán establecer o completar sus propias normas de funcionamiento».

Pues bien, y a la vista de dichas normas, los requisitos para la convocatoria y celebración de la sesión que, en su caso, acuerde la disolución del Consorcio deberá tener en cuenta lo previsto en las normas específicas previstas en los Estatutos que fijan las «particularidades» en este punto del Consorcio y que, lógicamente, no pueden ir en contra de lo previsto en la normativa estatal o autonómica, y, en lo no previsto específicamente en los artículos reproducidos, si será de aplicación la legislación básica estatal (dependiendo de cuando se adopte el Acuerdo) y la legislación autonómica para integrar las dudas interpretativas que puedan surgir.

Puede suceder que, por diversas circunstancias, no sea posible adoptar dichos acuerdos -muy específicamente carencia de quórum o falta de unanimidad- en estos supuestos, como se explicará más adelante, lo procedente será acudir a ejercer el derecho de separación por parte de aquella Administración que no desee permanecer en el mismo.

\section{El procedimiento ordinario de disolución de los consorcios}

Es preciso señalar que la extinción de un Consorcio no es un acontecimiento instantáneo, sino el resultado de un complejo proceso en el que se pone de manifiesto el doble aspecto obligacional e institucional de estas entidades, es decir, no sólo ha de resolverse el contrato social -en nuestro caso normalmente un Convenio- establecido entre los miembros del Consorcio con ocasión de su nacimiento, sino también se ha de eliminar la persona jurídica nacida de aquel contrato. Por consiguiente, la extinción sólo se alcanza tras varias fases tendentes a la resolución de los vínculos existentes entre el Consorcio y los miembros integrantes de éste, por un lado, y los que mantiene el Consorcio con terceros, de otro. Este largo proceso comienza con el acaecimiento de la causa de disolución y finaliza con la pérdida de la personalidad jurídica ${ }^{22}$.

De esta forma, son esenciales los siguientes pasos:

\section{A) Concurrencia de causa para disolver el Consorcio o resolución por Acuerdo unánime del Consejo Rector}

El inicio del proceso extintivo del Consorcio hemos de situarlo pues en la concurrencia de alguna de las causas de disolución que, o bien han sido previstas por el legislador, o bien fueron introducidas por los miembros de éste a través de los Estatutos. Los motivos disolutorios obedecen a principios configuradores diversos y operan de diferente manera como ahora comprobaremos.

Por una parte, el artículo 127.1 de la LRJSP -con anterioridad idéntica previsión venía establecida en la LRSP- establece que la disolución del consorcio produce su liquidación y extinción. En todo caso será causa de disolución que los fines para los que fue creado el consorcio hayan sido cumplidos.

Ambas partes coinciden en considerar que el artículo 15.3 de la Ley 15/2014 ha de interpretarse en el marco general del ordenamiento jurídico, de manera que en la determinación del sistema de fuentes de los consorcios habrán de tenerse en cuenta las competencias que ha asumido la Comunidad Autónoma en materia de consorcios y que forman parte del bloque de constitucionalidad. Se entiende por tanto que el Código Civil y el Texto Refundido de la Ley de Sociedades de Capital serían de aplicación supletoria respecto de las normas que así se dicten por la Comunidad Autónoma.

Y que se ha plasmado en la actual redacción del artículo 119 LRJSP que establece dicha preferencia normativa.

${ }^{22}$ Como indica TOSCANO GIL, F. (2017), pág. 2.696 la disolución, liquidación y extinción son, pues, términos distintos, con significados distintos. 
A esta primera causa enunciada por la LRJSP, los Estatutos de los Consorcios suelen añadir otras, a saber y a la vista de distintos Estatutos, se pueden señalar algunas: Por la transformación del Consorcio en otra Entidad, mediante acuerdo del Consejo Rector, con el quórum de las dos terceras partes, ratificado por los dos tercios de las entidades consorciales; por acuerdo unánime de todos los entes territoriales consorciados, etc.

Cabe señalar, por tanto y en principio, que no basta la voluntad unilateral de ninguna de las entidades que conforman el Consorcio para que se produzca la misma. Es preciso, dada la naturaleza también asociativa del Consorcio, que dicha voluntad sea ratificada por los miembros de éste (lo que se ve refrendado por el artículo 127.2 LRJSP).

Ahora bien, a estas causas establecidas en la Ley y en los Estatutos habrán de adicionarse, y si entendemos de aplicación la legislación societaria a la disolución de los Consorcios públicos, las establecidas legalmente en la norma civil además de la específicamente prevista en la LRJSP. Aunque, en este último supuesto, por un lado es preciso poner de relieve que algunas de las mismas difícilmente serán de aplicación dada la distinta naturaleza de la entidad consorcial respecto de una sociedad.

En cualquier caso, y será lo más común, la extinción de estas entidades se suele realizar mediante los respectivos acuerdos en la entidad consorciada y, a este respecto, es conveniente señalar que esta causa de disolución es una manifestación del carácter soberano del máximo órgano de la entidad consorciada. El acuerdo de los miembros como causa de disolución obedece a la base asociativa de carácter voluntario que tiene todo Consorcio: si el acuerdo de los socios da vida a la sociedad (associatio), una decisión social en sentido opuesto (dissociatio) es también causa de disolución como ha puesto de relieve la mayoría de la doctrina en el Derecho privado con referencia a la sociedad civil.

En conclusión, y como suelen detallar los Estatutos de los Consorcios, la voluntad social puede determinar, sin necesidad de que concurra ningún otro requisito, la disolución del Consorcio. Ahora bien, la trascendencia de la decisión social conmina al legislador a someter este acuerdo a un régimen agravado, mientras que para los demás motivos disolutorios, cuando se requiera un acuerdo, será normalmente suficiente alcanzar unas mayorías, sin que necesariamente se requiera la unanimidad, en este supuesto será exigible la misma.

\section{B) Procedimiento para la disolución tras la entrada en vigor de las normas básicas estatales para aquellos Consorcios que no hubiesen adoptado dicho acuerdo}

En estos supuestos, y para llegar a este punto, será preciso abordar los siguientes trámites:

a) Acuerdo unánime de los miembros del Consorcio (artículo 127.5 de la LRJSP y 49 de los Estatutos) que, en atención a su composición, requerirá de forma previa:

- Acuerdo del correspondiente órgano de gobierno, estatal o autonómico, cuando el Estado o la Comunidad autónoma participasen en este ${ }^{23}$.

- Acuerdo del Pleno de los Ayuntamientos, y en su caso de la Diputación Provincial, integrantes del Consorcio por mayoría absoluta (artículo $47.2 \mathrm{~g}$ ) de la Ley 7/1985, de 2 de abril, Reguladora de las Bases de Régimen Local) con, en su caso, la tramitación procedimental previa que se requiera en éstas más los informes preceptivos establecidos legalmente en estos supuestos ${ }^{24}$.

b) El máximo órgano de gobierno del consorcio al adoptar el acuerdo de disolución nombrará un liquidador -no ya una comisión liquidadora como se solía establecer con anterioridad a 2014- que será un órgano o entidad -persona jurídica, por tanto-, vinculada o dependiente, de la Administración Pública a la que el consorcio esté adscrito lo que conlleva, ulteriormente, que este órgano o entidad designe a un empleado público, a mi juicio un funcionario público dadas las tareas que ha de abordar, para que efectúe las operaciones materiales que conlleva la liquidación.

23 Con carácter general la legislación autonómica suele establecer un Informe de la Consejería de Hacienda correspondiente. Así sucede, por ejemplo, en el caso de la Junta de Andalucía donde el artículo 50 LAJA lo establece con carácter preceptivo.

${ }^{24}$ No sería preciso, en su caso, el de los órganos representativos de las organizaciones empresariales y sindicales con la mayoría requerida en sus Estatutos cuando no sean estrictamente entes consorciados sin perjuicio de que, como resulta en cierto modo frecuente, formen parte de su Consejo Rector. 
c) Publicación del Acuerdo de disolución (artículo 97.1 LRJSP) que no produce en forma automática la extinción ya que esta solo se produce cuando queda formalizada la liquidación (artículo 97.4).

La adopción del acuerdo de disolución de éste, con los requisitos expuestos, abre el período de liquidación, durante el cual el Consorcio mantiene su personalidad jurídica, pero que acarrea efectos sobre la propia entidad, sobre los miembros del Consorcio y sobre terceros ${ }^{25}$.

\section{La normativa supletoria: características generales de la sociedad civil, causas de extinción y su aplicación a los Consorcios públicos ${ }^{26}$}

Cabe señalar que, como ha puesto de relieve la doctrina civilista ${ }^{27}$, la sociedad civil es el contrato por el que dos o más personas se obligan a poner en común dinero, bienes o industria con el ánimo de partir entre sí las ganancias. Es, como ha puesto de relieve la doctrina, un contrato bilateral, o plurilateral, de gestión colectiva, consensual, oneroso y conmutativo ${ }^{28}$. Esta sociedad goza de personalidad jurídica salvo que mantenga secretos sus pactos y que cada socio contrate con terceros en nombre propio resultando,

${ }^{25}$ La situación de «sin actividad» de un consorcio puede venir motivada porque haya iniciado su proceso de disolución y no lo haya finalizado; o bien, pudiera ocurrir que no haya iniciado su proceso de disolución, pero que, sin embargo, sus órganos de gobierno y de gestión no se reúnan para la adopción de acuerdos y, en consecuencia, hayan cesado en el ejercicio de sus funciones, y no hayan aprobado, por tanto, los preceptivos presupuestos anuales para su funcionamiento.

En el primero de los casos, la adopción del acuerdo de disolución por el órgano competente del consorcio motiva su pase de situación «con actividad» a la de «sin actividad», por aplicación de la reglas de la Instrucción de Contabilidad vigentes, tanto autonómica, por ejemplo en el caso andaluz, aprobada por Orden de 30 de marzo de 2015, por la que se aprueba el Plan General de Contabilidad Financiera de la Administración de la Junta de Andalucía y de sus Agencias Administrativas y de Régimen Especial (Tercera parte. Cuentas Anuales), como local aprobada por Orden HAP/1781/2013, de 20 de septiembre, por la que se aprueba la Instrucción del modelo normal de contabilidad local (regla 4), que determinan que en los casos de disolución las cuentas anuales se refieran al período que va desde el 1 de enero hasta la fecha de disolución.

Tras dicho acuerdo, la gestión del consorcio corre a cago de la comisión liquidadora designada al efecto y que será la encargada de su liquidación o del liquidador si no se adoptó el acuerdo de disolución y se adopta éste tras la entrada en vigor de la LRJSP. Tal situación de sin actividad se prolonga en el tiempo hasta que se produce su extinción y desaparición de la vida jurídica, hecho que tiene lugar con la publicación del acuerdo de disolución o con la formalización de la liquidación en el supuesto de que dichos trámites se lleven a cabo una vez que entre en vigor la LRJSP.

Pues bien, en estos supuestos, y siempre que se haya adoptado el acuerdo de disolución, aún sin haberse publicado el mismo, es decir se hayan producido todos los efectos propios de dicho acuerdo -cesación de actividades y de relaciones entre sus miembros y terceros-, habrá de entenderse, aún cuando no se hayan producido la liquidación, que los mismos se sujetan a la normativa vigente en el momento de adopción del Acuerdo de disolución de acuerdo con lo dispuesto en el artículo $2.3 \mathrm{Cc}$ y los razonamientos anteriormente expuestos.

En el segundo de los supuestos, sin embargo, deberá acudirse a lo previsto en la normativa societaria, civil o mercantil como veremos, aplicable desde marzo de 2015 según expresamente prevé la LRSP ya que la no celebración de reuniones ordinarias de sus órganos rectores y, consiguientemente, la no adopción de acuerdos y no realización de actividad alguna no tiene, por si misma, eficacia constitutiva alguna para establecer dicha situación.

26 En efecto, es oportuno plantearse, asimismo, en este punto si es de aplicación la legislación mercantil ya que, de forma expresa, el artículo 119 solo se refiere al régimen de liquidación para hacer aplicable lo previsto en la legislación societaria por lo que, en una interpretación estricta, en la disolución de un Consorcio sería aplicable tan solo lo dispuesto supletoriamente para la sociedad civil en el Código Civil.

Por el contrario también podría entenderse que disolución y liquidación son dos fases de un mismo procedimiento abocado a la extinción del Consorcio. El complejo de relaciones jurídicas con terceros de que es sujeto el Consorcio o la colectividad de los miembros debe extinguirse antes de la extinción del Consorcio, es decir, el Consorcio debe ordenar su pasivo (exigible) y su activo (realizable) para determinar su estado patrimonial. La voluntad de disolver el Consorcio o la verificación de una causa que automáticamente lleva aparejada la disolución de éste abre un período, previo a la extinción, que consiste precisamente en la liquidación. Durante este período, el Consorcio sigue gozando, en su caso, de personalidad jurídica y se trataría de un Consorcio «sin actividad». Esto supone la realización de los activos sociales con los que cubrir el pasivo del Consorcio. Si el activo es superior al pasivo, el resto se repartirá entre los socios; si es inferior, los socios serán responsables de la diferencia. Una vez liquidada el Consorcio y repartidas, en su caso, las ganancias y aportaciones, se extingue.

Y, consecuentemente con esta segunda tesis enunciada, a la disolución y liquidación le sería de aplicación la legislación societaria de carácter mercantil.

En nuestra opinión, sin embargo, y dados los estrictos términos de la norma básica estatal (idénticos en la de 2014 y 2015), será de aplicación la legislación que se aplica a las sociedades civiles para la disolución y la societaria mercantil para el régimen jurídico de la liquidación lo que resulta plenamente coherente con la regulación establecida.

${ }_{27}$ Como resulta de sentido común, y es obvio, se sigue y se expone lo argumentado por la doctrina civilista en la materia civil y mercantil que se analiza en el presente estudio y de la que se da cuenta en el apartado de bibliografía.

28 TENA PIAZUELO, I. (2017), pág. 133. La misma se distingue plenamente de la sociedad mercantil o de la comunidad de bienes (pags. 160 y ss). 
en opinión de la doctrina y la jurisprudencia, esta segunda opción sociedades irregulares (STS 14 de julio de 2006).

En cuanto a su regulación normativa esta viene establecida por las disposiciones generales que se prevén en los artículos 1.665 a $1.678 \mathrm{CC}$, las obligaciones de los socios entre sí en los artículos 1.679 a 1.696 CC; las obligaciones de los socios para con terceros en los artículos 1.697 a 1.699 CC, y la extinción en los artículos 1.700 a $1.708 \mathrm{CC}$.

Dicha sociedad puede estar constituida, con carácter general, en forma particular y universal. La sociedad particular tiene por objeto cosas determinadas, su uso o sus frutos, o una empresa señalada o el ejercicio de una profesión o arte. La sociedad universal, a su vez, puede ser de todos los bienes presentes o de todas las ganancias, y si en el contrato no se especifica la clase de sociedad universal, se entenderá que la constituida lo es de todas las ganancias. Bien es cierto que, como se ha puesto de manifiesto, estas últimas son un mero residuo histórico ${ }^{29}$.

El hecho de que la sociedad civil, al menos la externa o dotada de personalidad jurídica, haya establecido vínculos con sus propios socios y terceros a lo largo de su existencia genera la necesidad de que su extinción no se pueda realizar en un solo acto sino que ha de desarrollarse a lo largo de un proceso dirigido precisamente a liquidar esos vínculos con terceros y a liquidar la misma entre sus socios. En ese sentido, a pesar de que los arts. 1.700 y siguientes del Código Civil simplemente se refieren a la extinción de la sociedad, lo más adecuado sobre todo desde un punto de vista lógico es poner de manifiesto la existencia de este proceso, que puede ser más o menos complejo o abreviado según la complejidad de la situación, y que se desarrolla en tres hitos básicos ${ }^{30}$ : la disolución, que vendría a ser la constatación de que la sociedad no puede seguir existiendo; la liquidación, proceso donde se procede a la desafectación del patrimonio social, satisfaciendo las deudas frente a terceros, reclamando sus créditos y liquidando a los socios su cuota de liquidación y, finalmente, la definitiva extinción de la sociedad, que sin mayores formalidades registrales se producirá cuando la sociedad haya efectiva y realmente satisfecho al último de sus acreedores.

En cuanto a las causas de disolución de la sociedad, si bien algunas operan de modo automático, según prevé el Código Civil, otras producen el mismo efecto por haberse así configurado en el contrato social; determinadas causas de extinción, legales o contractuales, requieren el reconocimiento unánime de su advenimiento por parte de todos los socios, o en su defecto declaración judicial al efecto.

De esta forma son causas de disolución de la sociedad: a) expiración del plazo, aunque cabe la prórroga; b) conclusión del negocio que constituye su objeto; c) pérdida de la cosa antes de su aportación a la sociedad; d) muerte o insolvencia de cualquiera de los socios, si bien cabe pacto de continuidad de la sociedad con el heredero del fallecido; e) voluntad de cualquiera de los socios, salvo que se haya constituido en forma mercantil o el término resulte de la naturaleza del negocio objeto de la sociedad ${ }^{31}$.

En estos supuestos, por tanto, la voluntad de un socio en el caso de que no se llegase a un acuerdo unánime en el procedimiento de disolución previsto estatutariamente produciría, en principio, la disolución de la sociedad. Y es que, efectivamente, la voluntad de cualquiera de los socios, con sujeción a lo dispuesto en los arts. 1.705 y 1.707 C. C., produciría la disolución. Pero si bien es cierto ello, no lo es menos que la efectividad de esta causa de disolución está en función del criterio temporal que rige a la sociedad según establece nuestro Código Civil.

En este último sentido, si ésta se constituyó por tiempo determinado, bien por disposición contractual bien por la naturaleza del negocio, ningún socio puede reclamar la disolución sino por justo motivo, como el incumplimiento por alguno de los socios de sus obligaciones, la inhabilitación para los negocios sociales, etc. La justicia del motivo alegado la determinan los tribunales (art. 1.707). En cambio, si no se ha pactado la sociedad por tiempo determinado o éste no resulta de la naturaleza del negocio objeto de la sociedad, cualquiera de los socios podrá solicitar la disolución de la misma siempre que lo haga de buena fe y en tiempo

29 TENA PIAZUELO, I. (2017), pág. 146, que opina que resulta difícil justificar la existencia de sociedades de carácter universal por las consecuencias sumamente rigurosas que comportan.

30 Estos tres momentos son los que identifica, con carácter general, la doctrina civilista. Puede verse, en este sentido, RONCALÉS SAMANES, J. (2017), "Extinción y liquidación de comunidades de bienes y sociedades civiles", en AAVV Comunidades de Bienes y Sociedad Civil, Tirant lo Blanch, Valencia, pág. 289. La propia jurisprudencia también lo ha manifestado así (STS 31 de mayo de 2006 ).

31 Como ha puesto de manifiesto MALDONADO RAMOS, J. (2014), "Código Civil Comentado, con jurisprudencia sistematizada y concordancias", El Derecho, Madrid, pág. 2.437 estas causas no tienen carácter taxativo y ha de incluirse el mutuo disenso de los socios como causa que determina el comienzo del período extintivo. 
oportuno. La denuncia del contrato debe ponerse en conocimiento de los demás socios (art. 1.705), lo que no implica, sin embargo, que la recepción haya de ser consentida ${ }^{32}$.

De esta forma, cabe concluir que las circunstancias dependientes de la voluntad del socio se conciertan en su facultad de denuncia del contrato (arts. 1.700.1.4 y 1.704 a 1.707 CC ). Esa facultad se reconoce como un derecho en el Código. Y es que esa visión del legislador del Código Civil le llevó a entender que sin uno de los socios la sociedad ya no podía seguir existiendo; de ahí que la denuncia, como el fallecimiento o cualquiera otra de las causas apuntadas, generase la extinción de la sociedad. Sin embargo, y he aquí el punto que se ha de subrayar, es que esa inicial conclusión resulta a todas luces excesiva y no debe haber reparo en que si las partes disponen otra cosa sea eso lo que deba valer. Así las cosas, lo más razonable será permitirle abandonar la aventura societaria -en nuestro caso el Consorcio- sin por ello perjudicar el interés de los socios y de la propia sociedad en seguir existiendo.

Dicho lo anterior, el sistema que de forma supletoria prevé el Código Civil se estructura, como ha puesto de relieve la doctrina, sobre dos ejes:

a) De un lado la denuncia ordinaria del art. $1.705 \mathrm{CC}$, que se configura como una declaración de voluntad unilateral ejercitable ad nutumen en aquellos casos en que no se haya previsto expresa o implícitamente término de duración para la sociedad. Su justificación es la interdicción de las vinculaciones perpetuas, especialmente inaceptables en casos en los que conllevan una responsabilidad personal e ilimitada por las deudas sociales. No obstante, en opinión de la doctrina civilista aun en defecto de pacto en contra, si el resto de socios manifiesta su deseo de continuar en la sociedad, esa denuncia debería reducirse a ser una denuncia parcial o ejercicio de un derecho de separación, so pena de considerar su ejercicio como abusivo.

En efecto, se razona por esta que si el interés del socio denunciante -en nuestro caso del miembro del Consorcio- se satisface del mismo modo mediante su mera separación que mediante la plena extinción del vínculo social, su pretensión en este último sentido se debería considerar como abusiva. De lo que se trata es pues de determinar ese último extremo: la indiferencia del socio acerca de la suerte de la sociedad. Por lo demás, la libertad de configuración contractual permite igualmente que se pacte la facultad de denuncia unilateral incluso en casos de duración determinada, si bien en ese supuesto la denuncia no tendrá otro valor que el de un derecho de separación. Lo que no es admisible de acuerdo con el fundamento del derecho es su exclusión o sujeción a justos motivos, ni siquiera aunque se permita la libre transmisión de la condición de socio, ya que como es patente, esa condición de socio no es en absoluto fungible y no supone por tanto una alternativa económica razonable al ejercicio del derecho de separación frente a la sociedad. Cosa distinta es la configuración convencional de las condiciones de validez de la renuncia a las que de inmediato se hará referencia: plazos de preaviso, periodo mínimo de vinculación a la sociedad, etc. si bien no se admitirán limitaciones contrarias al propio derecho que desnaturalicen su esencia libérrima, como periodos mínimos excesivos o la necesidad de justa causa.

Para que la renuncia surta efectos debe ser recepticia, ser hecha de buena fe y en tiempo oportuno de acuerdo con el art. $1.706 \mathrm{CC}$. Ninguna problemática surge respecto a la necesidad de que la denuncia sea conocida por el resto de socios. Tampoco plantea excesivos problemas la necesidad de que la denuncia no pueda tacharse de mala fe ${ }^{33}$, como ejemplifica el art. $1.706 \mathrm{CC}$ al indicar que lo es aquella de quien pretende apropiarse para sí sólo de un provecho que debería ser común, a lo que se suma aquella denuncia irrazonable o realizada con animus nocendi -disolución a toda costa a pesar de ofertas de adquisición o de resolución parcial-, contrarias a los actos propios, realizada en momentos cercanos a la constitución de la sociedad u otros similares. La consecuencia será que la denuncia no tendrá efecto y el resto de socios, ante esta infracción del deber de fidelidad del socio denunciante, podrán proceder a su exclusión de la sociedad a través de la resolución parcial del contrato (art. 1.706 I CC ). La oportunidad en la denuncia se cifra por el Código Civil en la necesidad de evitar los daños derivados de la finalización brusca e inesperada de la sociedad (interés negativo), no tanto los daños de no poder materializar sus expectativas de beneficios (interés positivo). En ese sentido es común la previsión de un plazo de preaviso que conjure de forma cierta el problema de la denuncia intempestiva.

b) De otro lado se encuentra el supuesto de la denuncia extraordinaria del art. $1.707 \mathrm{CC}$, prevista para los menos frecuentes casos de sociedades a término o con plazos de duración determinados y que no parece que sea el caso común aplicable a los Consorcios que no suelen tener fijado sino un plazo indeterminado.

32 RONCALÉS SAMANES, J. (2017), pág. 299 con cita de la SAP Málaga, núm. 853/2001, de 15 de diciembre.

33 En este sentido puede verse la STS 545/2001, de 4 de junio o la 184/2007, de 21 de febrero que detallan dichos conceptos de buena y mala fe por relación a esta denuncia. 
Pues bien, a la vista de lo expuesto, y atendiendo a lo explicado sobre la denuncia como forma de disolución del Consorcio por las causas establecidas en la normativa civil, considero que, dada la base asociativa del Consorcio y en el caso de que no se produjera un mutuo acuerdo, la manifestación de voluntad realizada por uno de los socios podría considerarse una denuncia de su participación en el Consorcio y, congruentemente con ello, el ejercicio de su derecho de separación del mismo, aunque sujeto este último al acuerdo del Consejo Rector del Consorcio, ya que uno de los socios no puede imponer, en un ente de naturaleza asociativa no se olvide, su voluntad unilateral inclusive en el supuesto de que éste estuviese adscrito al mismo.

En este sentido, realizada dicha actuación son de plena aplicación las previsiones estatutarias previstas específicamente a este respecto ${ }^{34}$.

Nada se indica sobre cuando dicha denuncia -ejercicio del derecho de separación- es efectiva. En este sentido, si con carácter general es efectiva la voluntad que se haya dirigido al resto de los miembros de una sociedad, realizada por escrito, con constancia de que se ha recibido y, de esta forma, según la doctrina y la mayor parte de la normativa general y sectorial, se estima que la voluntad se perfecciona por el hecho sólo de ser recibida por la otra parte según los medios aceptados en derecho, en los Consorcios públicos, ni en forma previa a la legislación de 2014 sobre ejercicio del derecho de separación ni con posterioridad a ésta, la renuncia podría ser considerada totalmente recepticia lo que no implica que pueda considerarse que abre el período de disolución, siempre que no exista acuerdo en contra para continuar del resto de los miembros, sin perjuicio de los acuerdos de liquidación que sea pertinente adoptar ${ }^{35}$.

La conclusión que puede alcanzarse tras la legislación de 2014 es que la efectiva separación del consorcio se producirá una vez determinada la cuota de separación, en el supuesto en que ésta resulte positiva, o una vez se haya pagado la deuda, si la cuota es negativa y para ello será preciso realizar las operaciones de liquidación pertinentes que han de aprobarse por el órgano máximo rector del Consorcio.

Luego, y por tanto, es preciso el acuerdo del máximo órgano del Consorcio, con o sin mayoría cualificada por no exigirla ni la Ley (a salvo de lo que establezcan los Estatutos,) y no basta la mera declaración de voluntad del socio en aquellos supuestos en que sea de aplicación la nueva normativa acontecida para el ejercicio del derecho de separación en 2014 y 2015 (artículo 13.2 y 126.2 respectivamente) lo que se desprende del inciso «se acordará por el consorcio la forma y condiciones en que tendrá lugar el pago de la cuota de separación, en el supuesto en que esta resulte positiva, así como la forma y condiciones del pago de la deuda que corresponda a quien ejerce el derecho de separación si la cuota es negativa» ${ }^{36}$.

34 Los Estatutos de los Consorcios suelen contemplar previsiones en este sentido. En concreto, y a título de ejemplo, el artículo 48 de los Estatutos del Consorcio de Marchena (los denominados Consorcios UTEDLT) prevé específicamente los siguientes requisitos:

a)Preaviso de un año dirigido a la Presidencia del Consorcio.

b) Estar al corriente en el cumplimiento de las obligaciones y compromisos anteriores respecto del Consorcio y garantizar el cumplimiento de las obligaciones pendientes con el mismo.

c) La separación no podrá comportar perturbación, perjuicio o riesgo evidente para la realización inmediata de cualquiera de los servicios o actividades del Consorcio, ni perjuicio para los intereses públicos al mismo encomendados.

35 En nada obstaculiza a esta conclusión el artículo 82 de la Ley 5/2010, de 11 de junio de Autonomía Local de Andalucía que se remite, para la modificación de estatutos, adhesión, separación y disolución del consorcio, a lo previsto en dicha ley para las mancomunidades, sin perjuicio de las particularidades derivadas de la naturaleza de los distintos entes consorciados.

En este sentido, el artículo 76 regula la separación de municipios mancomunados en los siguientes términos:

«1. Ningún municipio podrá separarse de la mancomunidad si, habiendo transcurrido el período mínimo de permanencia, mantiene deudas con la misma. A tal efecto, con la solicitud de separación deberá proceder a la liquidación de las deudas que se mantengan, al abono de la parte del pasivo de la mancomunidad que, en ese momento, le sea proporcionalmente imputable, y al pago de los gastos que se deriven de la separación.

2. El órgano de representación municipal de la mancomunidad, cuando considere que algún municipio haya incumplido gravemente las obligaciones establecidas en las leyes o en jos propios estatutos, y previa audiencia del mismo, podrá decidir su separación de la mancomunidad y la liquidación de las deudas pendientes, mediante acuerdo adoptado por el citado órgano por mayoría de dos tercios de sus componentes.

3. En los supuestos de separación en los que resulten deudas, obligaciones $v$ gastos sin satisfacer de un municipio a favor de la mancomunidad, previo acuerdo adoptado por el órgano de representación municipal, la mancomunidad podrá solicitar a la Administración de la Junta de Andalucía la retención de las cantidades que correspondiese entregar a favor de aquel, por una cuantía igual al importe adeudado, así como su ingreso compensatorio en la hacienda de la mancomunidad.

4. Adoptado el acuerdo de separación de un municipio, la mancomunidad lo remitirá, junto con la modificación producida en los estatutos, al Boletín Oficial de la Junta de Andalucía para su publicación, y se comunicará a la consejería competente sobre régimen local.»

36 Idéntica conclusión parece desprenderse, con carácter previo a la entrada en vigor de dicha normativa, en la normativa autonómica. A título de ejemplo, en la normativa andaluza, los artículos 82 y 76 de la LAULA imponen similar conclusión: carácter no recepticio de la denuncia, sin perjuicio de los efectos que esta pudiera tener para abrir el período de liquidación. 
En cualquier caso, conviene advertir que la separación de un miembro no implica la disolución del Consorcio y podría ocurrir que el mismo, por acuerdo del resto de miembros, siguiera existiendo lo que en determinados supuestos, aquellos en que dicho miembro aporte la mayor parte de la financiación, sin embargo será inviable.

\section{5. ¿Cabe la disolución judicial o lo procedente es el ejercicio del derecho de separación?}

Cabe señalar, en primer término, que solo tiene sentido preguntarnos por este supuesto cuando no sea posible adoptar el acuerdo de disolución según prevén los Estatutos por acuerdo unánime de los miembros del Consorcio.

Veamos que prevé la legislación privada respecto de este supuesto.

En el caso de la legislación civil el artículo 1.707 establece que no puede un socio reclamar la disolución de la sociedad que, ya sea por disposición del contrato, ya por la naturaleza del negocio, ha sido constituida por tiempo determinado, a no intervenir justo motivo, como el de faltar uno de los compañeros a sus obligaciones, el de inhabilitarse para los negocios sociales, u otro semejante, a juicio de los Tribunales ${ }^{37}$.

Estas causas de disolución desencadenan un procedimiento cuyo objetivo es lograr una decisión social en donde o bien asuma la finalización del proyecto en común o bien efectúe las modificaciones pertinentes para continuar. En ningún caso la sociedad se disuelve automáticamente, siempre será necesario una decisión social o al menos una omisión. Así pues, este procedimiento implica el sometimiento de la sociedad durante la disolución al principio mayoritario al permitir que los socios puedan eludir la apertura de la liquidación mediante la remoción del motivo disolutorio (véase STS 30 de junio de 1997).

La otra idea que preside el procedimiento disolutorio es lo que podríamos denominar el sistema de doble constatación, como ha indicado la doctrina civilista, cuya intención es dotarle de mayor seguridad jurídica, pues permite conocer con exactitud cuando se abre la liquidación, cuestión importante ante la dificultad de constatar la existencia de determinadas causas disolutorias ${ }^{38}$.

En fin, la primera parte del procedimiento disolutorio consiste en la apreciación de una realidad fáctica. Se trata aquí de precisar la existencia de una causa de disolución. Estamos en el terreno de los hechos, no de las voluntades. Pero el legislador, dada la trascendencia de la situación, no puede permitir que la decisión recaiga exclusivamente en los órganos de la sociedad. Para superar la inactividad, reticencia o incluso imposibilidad de la sociedad, la regulación vigente prevé como mecanismo subsidiario la posibilidad de declarar judicialmente la disolución ${ }^{39}$.

37 Por su parte, la legislación mercantil contempla para aquellos supuestos en que concurra una causa de disolución que, constatada en primera instancia la existencia de una causa de disolución, como itinerario lógico se produzca la convocatoria por parte de los administradores de una junta general donde se aborde la situación en el plazo de dos meses desde que se haya producido la causa de disolución. Si los administradores detectan la concurrencia del motivo disolutorio, están compelidos a resolver la situación, lo que comportará la adopción de decisiones sociales cuya competencia, como sabemos en la legislación mercantil, reside en la junta general. Ahora bien, también prevé que esta junta general sea solicitada por cualquier socio. La posición que ocupan los administradores en la sociedad implica que sean ellos en primer lugar los que aprecien la concurrencia de la causa de disolución. Sin embargo, para evitar la inhibición de los administradores, en especial cuando sea interesada, también se ha previsto que los socios puedan requerir a los administradores la convocatoria de la junta general.

38 Efectivamente, el procedimiento disolutorio surge con el acaecimiento de alguna de las circunstancias enumeradas en el artículo 262.1 de la Ley de Sociedades Anónimas o en el artículo 105.1 de la Ley de Sociedades de Responsabilidad Limitada. O contrario sensu, la ausencia de la causa supone la inexistencia del supuesto de hecho, por lo que no sería aplicable la consecuencia jurídica: el procedimiento de disolución. Por consiguiente, la constatación de su existencia adquiere una enorme importancia. Pero, además, el legislador es consciente de la dificultad que entraña en determinados supuestos el precisar si concurre el motivo disolutorio y desde qué momento aconteció. La tarea en ocasiones resultará sencilla (por ejemplo, se incluyó como causa de disolución estatutaria la muerte de un socio en nuestro caso la extinción), pero en otras ocasiones es terriblemente complicada (verbigracia, la imposibilidad de alcanzar el fin social).

Las posibilidades contempladas son diversas, pero en todas ellas siempre ha de concurrir una doble confirmación de la existencia de la causa. En primer lugar, son los administradores el órgano competente para determinar si se da o no un motivo disolutorio. Cuando la respuesta sea afirmativa, surge el deber de convocar una junta general donde se procederá posteriormente a establecer la existencia o no del motivo disolutorio. En caso de que la junta no aprecie esta circunstancia, aun concurriendo, los administradores son compelidos a buscar el refrendo del juez, quien disolverá la sociedad a través de una sentencia. Así mismo, cuando los administradores no convoquen la preceptiva junta, cualquier socio puede suplir esa omisión y solicitar su convocatoria que habrán de atender los administradores o podrá ser realizada por el juez. Por último, el artículo 262 de la Ley de Sociedades Anónimas y el artículo 105 de la Ley de Sociedades de Responsabilidad Limitada autorizan a cualquier interesado a pedir al juez la disolución de la sociedad. En definitiva, la disolución de la sociedad requiere una doble constatación de la existencia de la causa de disolución: administradores y junta general, socio y junta general, administradores y juez o interesado y juez. De este modo se dota de una mayor seguridad jurídica al sistema.

39 Las normas que la regulan conceden una doble legitimación activa para interponer la acción de disolución societaria a administradores e interesado. Por un lado, los administradores como garantes del procedimiento disolutorio están obligados a solicitarla. 
Tras la promulgación del régimen vigente en materia de sociedades de capital resulta mayoritariamente aceptado que la disolución se produce a partir del acuerdo social o de la sentencia y a idéntica conclusión puede llegarse con la legislación civil. Lo expuesto no resulta contradicho porque se reconozca que la aparición de la causa de disolución suponga el inicio del procedimiento disolutorio, siendo aquí donde reside su trascendencia. Las discrepancias se centran fundamentalmente a la hora de precisar cuál es el contenido del acuerdo o de la decisión judicial. Para los partidarios de la eficacia declarativa la junta general o el juez se limitan a emitir una declaración de ciencia. Por su lado, predicar la eficacia constitutiva implica dotar a la disolución de una estructura compleja: junto al motivo disolutorio ha de concurrir un acuerdo social o una sentencia judicial.

Pues bien, y expuesto el régimen jurídico de aplicación de la decisión judicial en el ámbito privado, cabe preguntarnos si éste podría entenderse de aplicación supletoria a los Consorcios públicos. Y, desde mi punto de vista, no sería de aplicación. No se trata ya, tan solo, de que la legislación civil o mercantil están pensando en la jurisdicción civil o mercantil y no en la jurisdicción contencioso-administrativa que serían en su caso donde habría de acudirse, sino que, junto a no contemplarse en la legislación administrativa dicha situación, el supuesto previsto para acudir en demanda de auxilio judicial para la constatación de la causa de disolución no se presenta en el ámbito público ya que, en caso de no acuerdo unánime de los miembros del Consorcio, la solución está en el ejercicio del derecho de separación que establece previsiones específicas respecto del ejercicio de este derecho por la Administración de adscripción ${ }^{40}$.

En efecto, el artículo 126 de la LRJSP, referido a los efectos del ejercicio del derecho de separación de un consorcio, prevé que:

1. El ejercicio del derecho de separación produce la disolución del consorcio salvo que el resto de sus miembros, de conformidad con lo previsto en sus estatutos, acuerden su continuidad y sigan permaneciendo en el consorcio, al menos, dos Administraciones, o entidades u organismos públicos vinculados o dependientes de más de una Administración.

2. Cuando el ejercicio del derecho de separación no conlleve la disolución del consorcio se aplicarán las siguientes reglas:

a) Se calculará la cuota de separación que corresponda a quien ejercite su derecho de separación, de acuerdo con la participación que le hubiera correspondido en el saldo resultante del patrimonio neto, de haber tenido lugar la liquidación, teniendo en cuenta el criterio de reparto dispuesto en los estatutos.

A falta de previsión estatutaria, se considerará cuota de separación la que le hubiera correspondido en la liquidación. En defecto de determinación de la cuota de liquidación se tendrán en cuenta, tanto el porcentaje de las aportaciones al fondo patrimonial del consorcio que haya efectuado quien ejerce el derecho de separación, como la financiación concedida cada año. Si el miembro del consorcio que se separa no hubiere realizado aportaciones por no estar obligado a ello, el criterio de reparto será la participación en los ingresos que, en su caso, hubiera recibido durante el tiempo que ha pertenecido al consorcio.

Se acordará por el consorcio la forma y condiciones en que tendrá lugar el pago de la cuota de separación, en el supuesto en que esta resulte positiva, así como la forma y condiciones del pago de la deuda que corresponda a quien ejerce el derecho de separación si la cuota es negativa.

La efectiva separación del consorcio se producirá una vez determinada la cuota de separación, en el supuesto en que ésta resulte positiva, o una vez se haya pagado la deuda, si la cuota es negativa.

\footnotetext{
Se cierra así el sistema con la responsabilidad por no disolución: los administradores, cuando la sociedad no logré alcanzar el acuerdo disolutorio, deben proceder judicialmente o responderán de las deudas sociales. Por otro lado, se concede la facultad a cualquier interesado. A diferencia de los administradores, sobre los interesados no pesa un deber, sino gozan de un derecho.

40 Y es que, como indica TOSCANO GIL, F. (2017), pág. 2.691 esta nueva regulación podría valorarse positivamente, en tanto la realidad haya evidenciado la dificultad de llevar a cabo la disolución de un consorcio, o la separación de uno de sus miembros, a falta de regulación específica.
} 
b) Si el consorcio estuviera adscrito, de acuerdo con lo previsto en la Ley, a la Administración que ha ejercido el derecho de separación, tendrá que acordarse por el consorcio a quien se adscribe, de las restantes Administraciones o entidades u organismos públicos vinculados o dependientes de una Administración que permanecen en el consorcio, en aplicación de los criterios establecidos en la Ley.

Por tanto, si ejercitado el derecho de separación no se adoptarán los acuerdos pertinentes por distintas circunstancias (muy específicamente la falta de quórum), dicha situación de inactividad habría de resolverse por los cauces generales del ordenamiento jurídico y, más específicamente, estudiando la viabilidad del ejercicio de una acción judicial al amparo del artículo 29 para conseguir hacer efectivo el derecho de separación.

\section{EL PROCEDIMIENTO DE LIQUIDACIÓN DE LOS CONSORCIOS EN LA LEY DE RÉGIMEN JURIDICO DEL SECTOR PÚBLICO, EN LA LEGISLACIÓN AUTONÓMICA Y EN LA LEGISLACIÓN SOCIETARIA}

Es procedente aclarar que, conforme a lo hasta aquí expuesto, las previsiones estatutarias rigen en defecto de lo establecido en la LRJSP y la legislación autonómica ${ }^{41}$, por lo que a todos los requisitos del acuerdo de disolución debiera unirse, como documentación sustantiva del Acuerdo de disolución, la forma y metodología que se vaya a seguir en ésta que puede ser o no la prevista en el RD Legislativo 1/2010 que sólo regirá en forma supletoria. Lo que, además, se ve corroborado por el artículo 127.3 LRJSP al que seguidamente nos referiremos.

\section{Las operaciones previas a los actos de liquidación: determinación de los criterios a seguir en esta}

La liquidación del Consorcio, según hemos ya expuesto, persigue extinguir las relaciones jurídicas entabladas con los terceros (liquidación del patrimonio) y con los miembros (división del patrimonio) para propiciar la extinción de éste. Teniendo en cuenta que por liquidación se entiende tanto el procedimiento dirigido a lograr la extinción de este (conjunto de operaciones materiales y jurídicas) como la situación en que se encuentra el Consorcio desde que se ha producido su disolución hasta que sobreviene su extinción.

La LRJSP, en su articulo 127, solo establece respecto de este punto dos previsiones:

3. El liquidador calculará la cuota de liquidación que corresponda a cada miembro del consorcio de conformidad con lo previsto en los estatutos. Si no estuviera previsto en los estatutos, se calculará la mencionada cuota de acuerdo con la participación que le corresponda en el saldo resultante del patrimonio neto tras la liquidación, teniendo en cuenta que el criterio de reparto será el dispuesto en los estatutos.

A falta de previsión estatutaria, se tendrán en cuenta tanto el porcentaje de las aportaciones que haya efectuado cada miembro del consorcio al fondo patrimonial del mismo como la financiación concedida cada año. Si alguno de los miembros del consorcio no hubiere realizado aportaciones por no estar obligado a ello, el criterio de reparto será la participación en los ingresos que, en su caso, hubiera recibido durante el tiempo que ha pertenecido en el consorcio.

4. Se acordará por el consorcio la forma y condiciones en que tendrá lugar el pago de la cuota de liquidación en el supuesto en que ésta resulte positiva.

Lo cierto es que, asimismo, en algunos Estatutos se prevé reglas especiales a estos efectos, de tal forma que el acuerdo de disolución en estos supuestos previstos estatutariamente ha de contener también

41 Si se trata de liquidaciones a las que le sea de aplicación el régimen jurídico anterior a lo previsto en la legislación básica estatal según los criterios de los que se ha dado cuenta más atrás, será de plena aplicación lo dispuesto en los Estatutos y lo previsto en la legislación autonómica que hasta ese momento sería de aplicación. Así, de conformidad con lo previsto en el caso de Andalucía, en el artículo 82 de la LAULA, hay una remisión al régimen de disolución y liquidación de las Mancomunidades que remite, a su vez, en el artículo 77 a lo dispuesto en los Estatutos. 
las pautas para realizar la liquidación por lo que son éstas y las establecidas en la LRJSP las que habrán de seguirse, y supletoriamente, las establecidas en el artículo 97 de la LRJSP y en el R. D. Legislativo 1/2010 (LSC) en defecto de las anteriores.

Por tanto, y a saber, la liquidación habrá de tener en cuenta:

- Los Estatutos, a los que remite expresamente la LRJSP, determinan que deberá establecerse en el proyecto presentado para la disolución del Consorcio la metodología y criterios a seguir para el cálculo de la cuota de liquidación de los miembros del Consorcio así como las disposiciones relativas a la reversión de bienes utilizados por el Consorcio.

- Los Estatutos suelen establecer, en los casos en que tienen previsiones al respecto, una regla principal, y es que el haber resultante de la liquidación se repartirá entre los miembros del mismo en proporción al importe de sus aportaciones para lo que es relevante lo dispuesto, a estos efectos, por el artículo 122.3 de la LRJSP. Las dudas que surjan sobre qué alcance ha de darse a la expresión «aportaciones», habrían de resolverse con arreglo a las pautas para el cálculo de la cuota de liquidación -que han de aprobarse con el acuerdo de disolución-y, en su defecto, serían de aplicación los criterios establecidos en el artículo 127.3 LRJSP y, en su caso, si fuera de aplicación dependiendo de la fecha en que se adopte el acuerdo de disolución de las establecidas en el artículo 14.3 de la LRSP ${ }^{42}$.

- Se exige acuerdo del Consorcio respecto de la forma y condiciones en que tendrá lugar el pago de la cuota de liquidación en el supuesto en que ésta resulte positiva (artículo 127.4 LRJSP y 14.4 Ley 15/2014) y la aprobación del balance de la liquidación (artículo 390 RD Legislativo 1/2010).

- En defecto de lo previsto en el artículo 127 LRJSP y los Estatutos serán de aplicación las previsiones establecidas en el artículo 97 LRJSP.

- En lo no previsto, y mucho me temo que no se llegará a ello, será aplicable el RD Legislativo 1/2010 (LSC).

En definitiva, la liquidación se somete a un régimen dispositivo -el que se establezca por los miembros del Consorcio atendiendo a lo establecido en el artículo 127.3- pero en caso de que sean insuficientes dichas previsiones será de aplicación el artículo 97 de la LRJSP y las previsiones del R. D. Legislativo 1/2010 (LSC) que recordemos aquí que, frente al Código de Comercio que impone asimismo un régimen dispositivo, establece un régimen imperativo ${ }^{43}$. Si bien lo cierto, y previendo la norma que solo será de aplicación supletoriamente a lo previsto en el artículo 97 (que implica la cesión global de activos) tendrá una muy escasa y relativa aplicación. Y es que es preciso recordar aquí, por su importancia, que en defecto de la normativa específica relativa a los Consorcios, y lo dispuesto en los Estatutos antes de la normativa mercantil, se aplica lo establecido en el artículo 97 de la LRJSP relativa a la extinción de los organismos públicos estatales que

42 Es sumamente relevante, en este punto, lo dispuesto en el artículo 122.2 de la LRJSP que prevé que a efectos de determinar la financiación por parte de las Administraciones consorciadas, se tendrán en cuenta tanto los compromisos estatutarios o convencionales existentes como la financiación real, mediante el análisis de los desembolsos efectivos de todas las aportaciones realizadas.

43 Frente al régimen eminentemente dispositivo de liquidación y división del haber social del Código de Comercio (art. 227), la legislación de sociedades de capital se caracteriza por una regulación autónoma y básicamente imperativa, en la que se trata de tutelar al máximo los intereses de acreedores y socios (Sentencia del Tribunal Supremo de 21 de marzo de 2003). Así se destaca en la Resolución de la Dirección General de los Registros y del Notariado de 22 de mayo de 2001:

(...) «Disuelta la sociedad se abre el periodo de liquidación salvo en los supuestos de sucesión a título universal en la totalidad de su patrimonio. La liquidación no es sino un procedimiento independiente, aunque derivado de la disolución, integrado por una serie de operaciones conducentes a extinguir sus relaciones jurídicas de la sociedad tanto con terceros como con sus propios socios para culminar con la extinción definitiva de la aquélla. Durante ese periodo la sociedad sobrevive, conservando su personalidad jurídica, pero sujeta a un status especial, por cuanto con la disolución se pone fin a su vida empresarial activa (...) para pasar a realizar las actuaciones tendentes tan sólo a lograr aquellos fines tal como resulta de la enumeración de facultades de los liquidadores (...).

A diferencia del régimen del Código de comercio sobre liquidación de sociedades en general de contenido eminentemente dispositivo, el establecido en la Ley de sociedades anónimas tiene carácter acusadamente imperativo. Y si bien la pervivencia de la sociedad durante el período de liquidación hace necesario mantener, a diferencia de lo que ocurre con los administradores, el funcionamiento de la junta general como órgano soberano de expresión de la voluntad social, sus competencias han de entenderse delimitadas por el fin a que la sociedad está abocada, de suerte que ni son omnímodas ni menos pueden contravenir normas de derecho necesario y así cabe deducirlo de la referencia que el artículo 271 de la Ley hace a que a la misma "darán cuenta los liquidadores de la marcha de la liquidación para que acuerden lo que convenga al interés común» y así lo ha venido entendiendo la jurisprudencia (SSTS de 5 de mayo de 1965, 1 de marzo de 1983 y 31 de mayo de 1985)». 
prevé un régimen muy específico: la cesión e integración global de activos y pasivos a la Administración de adscripción con subrogación de esta en todas las relaciones jurídicas que tuviera el organismo público con sus acreedores ${ }^{44}$.

\section{La figura del liquidador en los Consorcios}

El artículo 127 de la LRJSP dispone, en su apartado $2 .^{\circ}$, lo siguiente ${ }^{45}$ :

El máximo órgano de gobierno del consorcio al adoptar el acuerdo de disolución nombrará un liquidador que será un órgano o entidad, vinculada o dependiente, de la Administración Pública a la que el consorcio esté adscrito.

La responsabilidad que le corresponda al empleado público como miembro de la entidad u órgano liquidador será directamente asumida por la entidad o la Administración Pública que lo designó, quien podrá exigir de oficio al empleado público la responsabilidad que, en su caso, corresponda cuando haya concurrido dolo, culpa o negligencia graves conforme a lo previsto en las leyes administrativas en materia de responsabilidad patrimonial.

Aunque ya se ha apuntado no es baladí reseñar que, a diferencia de lo que acontece en las sociedades mercantiles, el liquidador es aquí una persona jurídica (órgano o entidad) lo que condicionará su régimen jurídico por lo que el régimen de responsabilidad se refiere, sin perjuicio de la acción de regreso establecida en este precepto para el empleado público que desarrolle dichas funciones. Además, aunque nombrado por el Consejo Rector, lo será a propuesta de la Administración de adscripción -ya que se trata de un órgano o entidad de ésta- lo que ha de ser interpretado en el sentido de que la norma, de aplicación imperativa por su carácter básico, pretende obviar cualquier problema de los que acontecen en el proceso de liquidación de sociedades mercantiles con respecto de este aspecto ${ }^{46}$.

44 Prevé dicho artículo:

1. Publicado el acuerdo de disolución al que se refiere el artículo anterior, o transcurridos los plazos en él establecidos sin que éste haya sido publicado, se entenderá automáticamente iniciada la liquidación.

2. La liquidación tendrá lugar por la cesión e integración global, en unidad de acto, de todo el activo y el pasivo del organismo público en la Administración General del Estado que le sucederá universalmente en todos sus derechos y obligaciones. El órgano o entidad designada como liquidador determinará, en cada caso, el órgano o entidad concreta, de la Administración General del Estado, donde se integrarán los elementos que forman parte del activo y del pasivo del organismo público liquidado.

La responsabilidad que le corresponda al empleado público como miembro de la entidad u órgano liquidador será directamente asumida por la entidad o la Administración General del Estado que lo designó. La Administración General del Estado podrá exigir de oficio al empleado público que designó a esos efectos la responsabilidad en que hubiera incurrido por los daños y perjuicios causados en sus bienes o derechos cuando hubiera concurrido dolo, culpa o negligencia graves, conforme a lo previsto en las Leyes administrativas en materia de responsabilidad patrimonial.

3. La Administración General del Estado quedará subrogada automáticamente en todas las relaciones jurídicas que tuviera el organismo público con sus acreedores, tanto de carácter principal como accesorias, a la fecha de adopción del acuerdo de disolución o, en su defecto, a la fecha en que concurriera la causa de disolución, incluyendo los activos y pasivos sobrevenidos. Esta subrogación no alterará las condiciones financieras de las obligaciones asumidas ni podrá ser entendida como causa de resolución de las relaciones jurídicas.

4. Formalizada la liquidación del organismo público se producirá su extinción automática.

45 En la regulación anterior a la LRJSP, cuando esta sea de aplicación, hay un cambio sustancial. En esta norma, desde su entrada en vigor, la figura del liquidador no es una persona jurídica. La norma parece apuntar a una persona física, bien que la doctrina científica ha admitido que este sea una persona jurídica en la esfera jurídico-mercantil en la medida que el principio que prevalece en el sistema de nombramientos es la primacía de la voluntad de los socios a través de cláusula estatutaria.

Al margen de dicha previsiones no se ofrece dato alguno adicional, salvo la remisión que la norma realiza a la normativa jurídicomercantil por lo que esta, con la necesaria adaptación a la naturaleza jurídico-pública del Consorcio, será de aplicación.

Con similitud a lo dispuesto en la legislación mercantil, la LRSP, prevé que, en caso de no nombramiento de un liquidador, se haga cargo de estas operaciones el administrador del Consorcio y, con ello, estableciendo un sistema de conversión legal de designación de liquidadores que, a diferencia del régimen jurídico de la liquidación de la sociedad anónima, evita que se produzca, una vez disuelta la sociedad, la ausencia o vacío del órgano de liquidación con las consecuencias perjudiciales que ello podría entrañar.

Mayor problemática presentaría, al no ser de aplicación supletoria la legislación mercantil, los supuestos en que habiéndose abordado la disolución del Consorcio en fecha previa a la entrada en vigor de la LRSP se produjera cualquier clase de problemática en torno a la figura del liquidador o liquidadores. En estos supuestos habría que estar a lo dispuesto por el Consejo Rector del Consorcio de acuerdo con sus Estatutos.

46 En idéntico sentido puede verse BARRERO RODRíGUEZ (2016): 87. Esta misma autora se hace eco de las enmiendas presentadas a los artículos que se analizan. 
De esta forma, y siendo liquidador un órgano o entidad, no ha lugar a la aplicación de las previsiones establecidas en el RD Legislativo 1/2010 (LSC) en caso de fallecimiento de éste a título de ejemplo y, en general, todo lo previsto en dicha norma habrá de ser interpretado y aplicado con este parámetro lo que redunda en que no cabrá la renuncia por parte del liquidador por recaer en un órgano o entidad de la Administración de adscripción.

De todas formas ello no excluye que pudieran ser de aplicación otras previsiones previstas en la legislación de sociedades como la prevista en los artículos $374,375,378$, y de forma matizada, a tenor de la naturaleza de la figura consorcial, los artículos 379, 380 y 381 ,

Obviamente las personas jurídicas, ya se trate de órganos sin personalidad o entes con personalidad jurídica, desarrollan sus funciones a través de personas físicas, los empleados públicos, que deberán ser nombrados con arreglo a lo establecido en la legislación de empleo público mediante los mecanismos de atribución transitoria de funciones públicas. Aunque la Ley nada aclara estimamos, por motivos de seguridad jurídica, que debiera de ser un funcionario de carrera dadas las funciones que se le atribuyen y lo dispuesto respecto de este punto por el Estatuto Básico del Empleado Público.

Todo ello, sin perjuicio, de que en apoyo de dicha gestión se pueda proceder a acudir a ayuda o auxilio externo para las operaciones materiales de liquidación, mediante un contrato de servicios, y de acuerdo y con los requisitos establecidos en el Texto Refundido de la Ley de Contratos para las Administraciones Públicas. Respecto de este punto sería conveniente precisar en los pliegos de condiciones o documento análogo el régimen de responsabilidad en que se podría incurrir por las operaciones materiales realizadas por los ejecutores del contrato.

\section{La responsabilidades en que incurren los liquidadores}

Ha de tenerse en cuenta, respecto de este punto, que los liquidadores pueden incurrir en responsabilidad si se demuestra haber actuado con fraude o negligencia grave en el desempeño de su cargo, habiendo causado perjuicio a los accionistas aquí miembros del Consorcio.

En el supuesto de que la legislación de aplicación sea la legislación mercantil (acuerdos de disolución adoptados entre la entrada en vigor de la LRSP y, hasta el 2 de octubre de 2016 con la entrada en vigor de la LRJSP,) habrá que estar a lo dispuesto en ésta.

En la regulación decimonónica de la responsabilidad civil de los liquidadores, la finalidad de la acción contemplada en los artículos 342 del Código de Comercio de 1829 y en el 231 del de 1885 era la reintegración del patrimonio social («haber social», «haber común») por los daños causados con dolo o negligencia grave, esto es, se recogía una acción social. En la Ley de Sociedades Anónimas de 1951 se produce un cambio de la técnica legislativa instaurando en su artículo 169 una acción de naturaleza individual a favor de accionistas y terceros, esto es y como indica la doctrina, una acción de resarcimiento directo de los daños sufridos por aquéllos a causa de una actuación fraudulenta o gravemente negligente en el desempeño del cargo de liquidador ${ }^{47}$. El texto de dicho precepto se recogió literalmente en el artículo 279 de la Ley de Sociedades Anónimas, pero no se consideró un tratamiento equiparable con los administradores en relación a los criterios de imputación exigibles a un ordenado comerciante y representante leal.

Ciertamente, la exigencia de un grado de imputación cualificado («fraude o negligencia grave), excluyendo la culpa leve, es incongruente con el deber de diligencia que ha de presidir su actuación y contrasta significativamente con el sistema instaurado para los administradores sociales, pero, con la salvedad de esta especialidad, resulta preciso para construir con el recurso a la analogía, un régimen de responsabilidad coherente la integración del artículo 279 de la Ley de Sociedades Anónimas con la disciplina legal o marco normativo general de la responsabilidad orgánica de los administradores sociales (arts. 133 y ss.).

En la actualidad, el artículo 397 del R. D. Legislativo 1/2010 (LSC) establece respecto de la exigencia de responsabilidad a los liquidadores tras la cancelación de la sociedad ${ }^{48}$ :

Los liquidadores serán responsables ante los socios y los acreedores de cualquier perjuicio que les hubiesen causado con dolo o culpa en el desempeño de su cargo.

47 GARRIGUES/URÍA, (1976): 914 y ss.

48 Artículo 397 redactado por el número veinticinco del artículo primero de la Ley 25/2011, de 1 de agosto, de reforma parcial de la Ley de Sociedades de Capital y de incorporación de la Directiva 2007/36/CE, del Parlamento Europeo y del Consejo, de 11 de julio, sobre el ejercicio de determinados derechos de los accionistas de sociedades cotizadas (BOE, 2 agosto, con vigencia 2 de octubre de 2001). 
Si bien, en el caso de los acuerdos de disolución adoptados con posterioridad a la LRJSP, y a diferencia del régimen anteriormente expuesto, hay que tener en cuenta que responde, con arreglo a los requisitos y supuestos establecidos para la responsabilidad patrimonial, la Administración a la que se haya adscrito el Consorcio que es quien designa al empleado público que se hace cargo de las responsabilidad de las operaciones liquidadoras, sin perjuicio de la acción de regreso que dicha norma prevé frente a éste ${ }^{49}$.

\section{Las operaciones jurídicas y materiales de la liquidación del Consorcio}

Las operaciones de liquidación del patrimonio de un Consorcio, en los supuestos en que ya sea de aplicación la legislación de sociedades de forma supletoria (a partir de marzo de 2015), no difieren sustancialmente de las de una sociedad, con las especialidades propias ya vistas y las derivadas de su específica naturaleza de ente público ${ }^{50}$. En cualquier caso, y con anterioridad a dicha fecha, tampoco difieren sustancialmente respetando lo establecido en los Estatutos.

El liquidador asumirá las funciones a que se refieren los artículos 383 y siguientes de la Ley de sociedades de capital. Estos preceptos no sólo contienen normas sobre la posición jurídica de los liquidadores, sino también reglas para la liquidación y división del haber social ${ }^{51}$.

De un lado, se establece que los liquidadores llevarán la contabilidad, libros, documentación y correspondencia de la sociedad (art. 386 LSC), velarán por la conservación de su patrimonio (art. 375 LSC), realizarán las operaciones pendientes y podrán llevar a cabo las nuevas que sean necesarias para la liquidación de la sociedad (art. 384 LSC; v., por el contrario, art. 228 CCom) y podrán concertar transacciones y arbitrajes, ostentando la representación de la sociedad para el cumplimiento de los fines liquidatorios (art. 379 LSC). En relación con el poder de representación de los liquidadores, salvo disposición contraria de los estatutos, corresponderá a cada liquidador individualmente, extendiéndose a todas aquellas operaciones que sean necesarias para la liquidación de la sociedad.

De otro lado, la especificidad de sus funciones radica en la realización de las operaciones de liquidación. Así, les corresponde:

a) Formular el inventario y balance de la sociedad, con referencia al día en que se hubiera disuelto (art. 383 LSC), lo que marca la transición entre el período de explotación y el de liquidación.

b) Enajenar los bienes sociales de acuerdo con la legislación de patrimonio de la Comunidad Autónoma de Andalucía o en su caso establecer la reversión de los mismos ( Estatutos, art. 387 LSC y 122.5 LRJSP). El Tribunal Supremo ha declarado en diversas sentencias que la finalidad esencial de las operaciones liquidadoras es obtener dinero (SSTS de 5 de febrero y 15 de julio de 2003) ${ }^{52}$.

c) Percibir los créditos sociales y pagar las deudas sociales.

Estas operaciones constituyen las operaciones típicas de liquidación del activo: pagar a los acreedores, que no es sino realizar la liquidación del pasivo y pagar a los miembros del Consorcio, es decir, llevar a cabo la división del patrimonio, pudiendo consignar el importe de los créditos y asegurando el pago de los no vencidos.

Los liquidadores deben, además, hacer llegar periódicamente a conocimiento de los miembros y de los acreedores el estado de la liquidación.

Las funciones de los liquidadores son, pues, como las de los administradores, funciones de simple administración y de representación, si bien dirigidas a la extinción de las relaciones jurídicas con los terceros y con los socios ${ }^{53}$.

49 Solución que, en opinión de MONTOYA MARÍN (2016), va en contra de los criterios que deben informar el buen gobierno y la buena administración.

50 Un estudio exhaustivo de esta puede encontrarse en AA.VV (2012), La liquidación de las sociedades mercantiles (dir. Ángel Rojo y Emilio M. Beltran), Tirant lo Blanch, Valencia.

51 En extenso puede verse respecto de la figura y funciones de los liquidadores VALPUESTA GASTAMINZA, E. (2013), pág. 1.014 y ss.

52 (...) «en la fase de liquidación precisamente toda la actividad social persigue la conversión del activo social en dinero y como las reglas relativas a la liquidación son imperativas, nada puede reprocharse a la liquidadora que se limita a aplicar la regla contenida en el artículo 272.d) de la Ley de sociedades anónimas» (STS de 30 de octubre de 2007).

53 La Resolución de la Dirección General de los Registros y del Notariado de 22 de mayo de 2001 establece que: "En la enumeración que el artículo 272 de la Ley hace de las facultades de los liquidadores encontramos, aparte de las de tipo formal, las que implican 
En todo caso, la representación del Consorcio durante el proceso de liquidación y la facultad de satisfacer a los miembros el haber social resultante corresponden al liquidador.

\section{Activo y Pasivo sobrevenido y responsabilidad frente a deudas futuras}

En el supuesto de que producida la liquidación, y aprobada esta por el Consejo Rector, apareciesen activos o pasivos que no había sido objeto de liquidación, habría que distinguir, al menos, tres supuestos:

a) En el supuesto ordinario, habría que estar a lo dispuesto en los Estatutos y en el acuerdo de disolución y, a falta de previsión específica, parece lógico que sea la cuota de liquidación que corresponda a cada entidad la determinante para resolver dicha cuestión.

b) Que se hubiese aplicado lo previsto en el artículo 97 al que anteriormente nos referimos (un supuesto de cesión global de activos y pasivos) en que sería la Administración de adscripción a la fecha de adopción del acuerdo de disolución la que se haría cargo de las mismas.

c) En el supuesto de que fuera de aplicación la legislación mercantil, en defecto de las anteriores, por haber sido adoptado el acuerdo de disolución una vez que entró en vigor la LRSP -igualmente para aquellos adoptados tras la entrada en vigor de la LRJSP-, los artículos 398 y 399 de la Ley de Sociedades de Capital ofrecen una respuesta de aplicación a dicho supuesto:

- Por una parte, el artículo 398, y en relación al activo sobrevenido, establece que si aparecieran bienes sociales los liquidadores deberán adjudicar a los antiguos socios la cuota adicional -en proporción habrá que entender a la cuota de liquidación- que les corresponda, previa conversión de los bienes en dinero cuando fuere necesario.

- De otro lado, el artículo 399, y respecto del pasivo sobrevenido, ofrece otra regla: los antiguos socios responderán solidariamente de las deudas sociales no satisfechas hasta el límite de lo que hubieran recibido como cuota de liquidación.

Todo ello sin perjuicio de la responsabilidad, a salvo de previsión estatutaria, en las formas conjuntas de actuación de las Administraciones públicas sea solidaria.

Y es que, en el ámbito jurídico público, y más en concreto respecto de las formas de actuación de las Administraciones públicas en forma colaborativa, el artículo 33 de la LRJSP no deja lugar a dudas y establece una responsabilidad solidaria, salvo que los Estatutos del Consorcio establecieran una fórmula distinta. Lógicamente todo ello en garantía de los deudores y, sin perjuicio, de que posteriormente cada Administración haya de responder en proporción a su participación.

Si dicha cuestión podría afectar a la separación, por no poderse liquidar de forma completa las deudas sociales, a mi juicio no quedaría afectada respecto de las futuras y no conocidas que fueran imputables al miembro del Consorcio hasta la fecha de su separación (sin perjuicio de que haya de responder de las mismas en proporción a su participación). Las deudas futuras, y posteriores a que se haga efectivo el ejercicio del derecho de separación, obviamente no serían imputables al mismo.

\footnotetext{
la realización de los actos necesarios para llevar a cabo la liquidación, con referencia especial a la culminación de las operaciones pendientes, al margen de la excepcional posibilidad de realizar aquellas nuevas que la liquidación exija, la enajenación de los bienes sociales, el cobro de los créditos y dividendos pasivos y el pago a los acreedores sociales y a los socios "ateniéndose a las normas que se establecen en esta Ley» (art. 272 g). Entre esas normas a que ha de sujetarse el pago de acreedores y socios están no sólo las relativas a la forma sino también el orden y tiempo en que han de hacerse, extremos a que se refiere el artículo 277 cuando, pese a remitir a la hora de proceder a la división del haber social a lo previsto en los estatutos o acordado por la junta general, impone que «en todo caso» se tengan en cuanta entre otras las siguientes reglas: "Los liquidadores no podrán repartir entre los socios el patrimonio social sin que hayan sido satisfechos todos los acreedores o consignado el importe de sus créditos. Se establece por tanto un orden imperativo en la extinción de las relaciones jurídicas existentes al tiempo de la disolución de la sociedad, de suerte que habrán de serlo en primer lugar las establecidas con terceros, sea a través del pago o consignación del importe de sus créditos, y sólo una vez ello haya tenido lugar, las correspondientes a los socios (Resolución de 16 de julio de 1998). Y esta prohibición legal de reparto anticipado ha de entenderse aplicable no sólo al que tenga lugar de modo directo, a través de anticipos a cuenta de la cuota de liquidación, sino también por vía indirecta, sea por medio de adquisición de acciones por la propia sociedad, sea la condonación de dividendos pasivos acordados o cuya exigibilidad pueda ser necesaria para el pago de las deudas [art. 272.e)] o a través de una reducción del capital social con devolución de aportaciones. Supone, en definitiva, un reforzamiento de la posición de los acreedores superior a la que se establece para el caso de reducción de capital por cuanto no está condicionada al conocimiento por los mismos de la reducción del patrimonio social ni al ejercicio en base a tal conocimiento de un posible derecho de oposición".
} 
Respecto de las conocidas e imputables al período anterior a la efectividad del derecho de separación, pero no cuantificadas por no ser posible a dicha fecha, debería de adoptarse alguna cláusula específica en la liquidación correspondiente.

\section{LA CESIÓN GLOBAL DE ACTIVOS COMO PROCEDIMIENTO DE EXTINCIÓN DE LOS CONSORCIOS EXISTENTES}

La legislación mercantil regula la cesión global de activo y pasivo como operación simplificada de liquidación, regulada en parte de forma similar a la fusión, como operación societaria adoptada por acuerdo mayoritario de la Junta general de la sociedad cedente, de transmisión de todo el patrimonio social, que se produce con la inscripción de la extinción de la sociedad.

Dicha forma de liquidación, podríamos decir que extraordinaria, se ha incorporado a la legislación administrativa con un perfil propio y, en este sentido, el artículo 127, apartado 5, de dicha norma prevé que:

5. Las entidades consorciadas podrán acordar, con la mayoría que se establezca en los estatutos, o a falta de previsión estatutaria por unanimidad, la cesión global de activos y pasivos a otra entidad del sector público jurídicamente adecuada con la finalidad de mantener la continuidad de la actividad y alcanzar los objetivos del consorcio que se extingue. La cesión global de activos y pasivos implicará la extinción sin liquidación del consorcio cedente ${ }^{54}$.

Pero, asimismo y como hemos visto, dicha opción se establece como alternativa cuando, con arreglo a lo dispuesto para el procedimiento de liquidación, y en defecto de lo previsto en el artículo 127 de la LRJSP y los Estatutos, publicado el acuerdo de disolución, o transcurridos los plazos para su publicación, este no se haya realizado de forma efectiva (artículo 97 LRJSP).

La cesión global de activo y pasivo venía regulada con anterioridad de una forma muy limitada, y exclusivamente en sede de liquidación, concretamente la encontrábamos en los antiguos artículos 266 de la Ley de Sociedades Anónimas (LSA), 117 de la Ley de Sociedades de Responsabilidad Limitada (LSRL) y 246 del Reglamento Registro Mercantil (RRM).

De esta forma, no fue hasta la aprobación de la Ley 3/2009, de 3 de abril, sobre modificaciones estructurales de las sociedades mercantiles (LME) en la que la cesión global de activo y pasivo pasa de ser una mera fórmula de liquidación, para convertirse en una auténtica operación de modificación estructural, junto a la transformación, fusión y escisión ${ }^{55}$.

De esta forma, debe entenderse como cesión global, y aunque en la norma no aparece un concepto claramente definitorio el mismo puede extraerse del contenido del artículo 81 del texto legal, como la transmisión en bloque de todo el patrimonio de una sociedad inscrita, por sucesión universal, la cual podrá realizarse a uno o varios socios o terceros, a cambio de una contraprestación que no podrá consistir en acciones, participaciones o cuotas de socio del cesionario.

Ha de tenerse en cuenta este dato ya que la remisión que se realiza por la legislación administrativa lo es tan solo a la normativa contemplada en el RD Legislativo 1/2010 (LSC) y no a esta Ley por lo que, en principio y salvo mejor opinión, no sería de aplicación al tratarse de una remisión expresa y determinada a una norma y ofrecer la legislación administrativa una norma propia como forma de extinción extraordinaria del Consorcio.

En el caso de los Consorcios públicos, el artículo 97 LRJSP -de aplicación por disposición expresa del artículo 119 LRJSP- prevé que la liquidación tendrá lugar por la cesión e integración global, en unidad de

54 NIETO GARRIDO (2016): pág. 2.020, considera muy positiva dicha previsión pues, razona la autora, que a falta de previsión expresa viene a dar seguridad jurídica cuando no exista previsión en la normativa autonómica o estatutaria.

55 En la actualidad, la cesión global está recogido entre los artículos 81 a 91 de la LME, y como señala el Preámbulo de esa Ley «el ingreso de la cesión global de activo y pasivo entre las modificaciones estructurales, rompe amarras con aquella concepción que limitaba esta operación al ámbito propio de la liquidación y, al mismo tiempo, proporciona un instrumento legislativo más para la transmisión de empresas», afirmando que ahora se permite que una sociedad transmita en bloque todo su patrimonio a otra u otras por sucesión universal a cambio de una contraprestación que no podrá consistir en acciones, participaciones o cuotas del cesionario.

Como sabemos, las modificaciones estructurales de las sociedades mercantiles son «aquellas alteraciones de la sociedad que van más allá de las simples modificaciones estatutarias para afectar a la estructura patrimonial o personal de la sociedad», tal y como señala el Preámbulo de la LME, y que comprenderían la transformación, la fusión y la escisión, como originarias, a las que se añadiría en este momento la cesión global de activo y pasivo. 
acto, de todo el activo y el pasivo del organismo público en la Administración General del Estado que le sucederá universalmente en todos sus derechos y obligaciones (en otros supuestos será la Administración de adscripción). El órgano o entidad designada como liquidador determinará, en cada caso, el órgano o entidad concreta, de la Administración General del Estado, donde se integrarán los elementos que forman parte del activo y del pasivo del organismo público liquidado.

Por otro lado, prevé en su apartado $3 .^{\circ}$ que la Administración General del Estado en este supuesto ya que en el procedimiento ordinario habrá que estar a lo dispuesto en el artículo 127 LRJSP, Estatutos y supletoriamente lo establecido en el RD Legislativo 1/2010- quedará subrogada automáticamente en todas las relaciones jurídicas que tuviera el organismo público con sus acreedores, tanto de carácter principal como accesorias, a la fecha de adopción del acuerdo de disolución o, en su defecto, a la fecha en que concurriera la causa de disolución, incluyendo los activos y pasivos sobrevenidos. Esta subrogación no alterará las condiciones financieras de las obligaciones asumidas ni podrá ser entendida como causa de resolución de las relaciones jurídicas.

Dicha opción, a instar por la Administración de adscripción, requerirá, por tanto, y al menos, de tres trámites:

a) Elaboración del proyecto de cesión global de activos y pasivos.

b) Informes preceptivos que sean necesarios ${ }^{56}$.

c) Acuerdo unánime de los miembros del Consorcio (artículo 127.5 de la LRSP y 49 de los Estatutos) que, en atención a su composición, requerirá de forma previa:

- Acuerdo de los órganos de gobierno, estatal o autonómico, respecto de la elección de esta opción.

- Acuerdo del Pleno de los Ayuntamientos, o del Pleno de la Diputación Provincial si participa en el Consorcio por mayoría absoluta (artículo $47.2 \mathrm{~g}$ ) de la LRBRL con, en su caso, la tramitación procedimental previa que se requiera en éstas más los informes preceptivos establecidos legalmente en estos supuestos.

d) Publicación del Acuerdo de disolución (artículo 97.1 LRJSP).

Es relevante destacar, y para finalizar esta exposición, que la opción por esta forma extraordinaria de extinción, solo aplicable desde la normativa aprobada en 2014 o si así se hubiese previsto en los Estatutos, no queda condicionada a la liquidación del Consorcio (art. 127.5 LRJSP)

\section{BIBLIOGRAFÍA}

ALONSO MÁS, M. J. (2005) "Comentario al artículo 3 LBRL", en DOMINGO ZEBALLOS, M. J. (coord.), Comentarios a la Ley básica de régimen local (Ley 7/1985, de 2 de abril, reguladora de las bases del régimen local), $2 .^{a}$ ed., Thomson-Cívitas, Madrid, págs. 185-187.

APARICIO CARRILLO, E. J. (2003), Los socios ante el patrimonio de la sociedad civil en liquidación, Servicio de Publicaciones de la Universidad de Jaén. Jaén, 2003. 352 páginas.

AA.VV (2012), La liquidación de las sociedades mercantiles (dirs. Ángel Rojo y Emilio M. Beltran), Tirant lo Blanch, Valencia.

BARRERO DOMÍNGUEZ, C. (2002) "Los conceptos de mancomunidades y consorcios: necesidad de delimitación y diferenciaciones", Revista Andaluza de Administración Pública, 45: 81 y ss.

- (2016), "Los Consorcios Administrativos ante un nuevo régimen jurídico", Revista Andaluza de Administración Pública, núm. 94, 2016.

BATALLER, J., (2009) “LA DISOLUCIÓN”, en Disolución y liquidación de sociedades mercantiles, Rojo, Ángel y Beltrán, y Emilio M. (directores), Campuzano, Ana-B. (coordinadora). Ed. Tirant lo blanch, Valencia, 2009, págs. 23 a 93.

CAmpuzANo, A. B. (2011), "La división del patrimonio social", en Rojo, Ángel y Beltrán, Emilio (directores), Campuzano, Ana B. (coordinadora), La liquidación de las sociedades mercantiles. Ed. Tirant lo blanch, Valencia, 2011, págs. 275 a 296.

CASTILLO BLANCO, F. A. (1991) "Los consorcios de entidades locales: análisis y evolución a la luz de la nueva legislación de régimen Local" RAP, 124: 397 y ss.

56 En el caso andaluz de la Consejería de Hacienda de la Junta de Andalucía (artículo 50 LAJA). 
- (2001), "Los Consorcios Administrativos: especial referencia a los consorcios de entidades locales en la legislación andaluza", Revista Andaluza de Administración Pública, 42: 95 y ss.

- (2014), "La nueva regulación de los consorcios públicos: interrogantes y respuestas sobre el régimen jurídico de su personal", Revista Vasca de Administración Pública, núms. 99-100.

- (2017), "La incidencia de la nueva Ley de Régimen Jurídico del Sector Público en los instrumentos de cooperación del Estado Autonómico: especial referencia a los consorcios públicos", Diario de Derecho Municipal, IUSTEL, Edición de 10/03/2017.

DOMÉNECH GARRET, C. (2008), Vademécum de derecho civil y procesal civil, Tirant lo Blanch, Valencia.

FERREIRA FERNÁNDEZ, J. (2009), "Los consorcios del sector público autonómico: naturaleza y características", Revista de Estudios de la Administración Local y Autonómica, núm. 310. DOI: 10.24965/reala.v0i310.9682.

GARCÍA MÁS, F. J. (2003) "La sociedad civil, en Instituciones de derecho privado" (coord. por Juan Francisco Delgado de Miguel), vol. 6, tomo 1, 2003, Derecho de sociedades. págs. 195-288.

GARCíA RUBIO, F. (2015) "Los consorcios locales en el proyecto de ley de Régimen Jurídico del sector público. Reflexiones necesarias", Documentación Administrativa (Nueva Época), núm. 2.

GARRIGUES/URÍA, (1976), Comentario a la Ley de sociedades anónimas, II, Madrid, págs. 914 y ss.

GIRÓN TENA, J., (1976) Derecho de Sociedades, 1976.

LARA, R., (2009) "La extinción de la sociedad”, en Rojo, Ángel y Beltrán, Emilio M. (dirs.), y Campuzano, Ana-B. (coord.), Disolución y liquidación de sociedades mercantiles. Ed. Tirant lo blanch, Valencia, 2009, págs. 335 a 366.

LASARTE ÁLVAREZ, C. (1984), "La sociedad civil”, Diario La Ley, 1984, pág. 1.250, tomo 4. Editorial La Ley.

LÓPEZ MENUDO, F. (1995), "Servicios municipales y gestión consorciada", en Pedro Escribano Collado (coord.) Jornadas de Estudios sobre consorcios locales: Temas de Administración Local. Ediciones Adhara, S. L. 1-34.

MACHADO, J., (2009), "Los liquidadores de las sociedades de capital”, en Rojo, Ángel y Beltrán, Emilio M. (dirs.), y Campuzano, Ana-B. (coord.), Disolución y liquidación de sociedades mercantiles. Ed. Tirant lo blanch, Valencia, 2009, págs. 163 a 212.

MACÍAS CASTILLO, A. (2006), "Liquidación de sociedad civil”, Actualidad Civil, núm. 18, quincena del 16 al 31 Oct. 2006, pág. 2.244, tomo 2, Editorial La Ley.

MALDONADO RAMOS, J. (2014), Código Civil Comentado, con jurisprudencia sistematizada y concordancias, El Derecho, Madrid.

MARTÍNEZ LÓPEZ-MUÑIZ (1974), Los Consorcios en el Derecho español - Análisis de su naturaleza jurídica. Madrid: IEAL.

MARTÍN MATEO, R (1971) "Los consorcios como institución jurídica”. RAP, 161: 9 y ss.

- (1987a), Entes locales complejos: mancomunidades, agrupaciones, consorcios, comarcas, áreas metropolitanas, Trívium., Madrid, 1987, pág. 22;

- (1987b), Entes locales complejos. Madrid: Trivium.

- (1992), "Los Consorcios locales: una institución en auge", RAP, 129: 8 y ss.

MONTOYA MARÍN, E. (2016), "Los instrumentos de colaboración público-privada en la gestión de servicios de interés general: el consorcio local y ¿su racionalización?”, págs. 160-182, en el volumen colectivo Servicios de interés general, colaboración público-privada y sectores específicos. Editorial Tirant lo Blanch y G. Giappiachelli Editore, Brescia.

MORILLO-VELARDE PÉREZ, J. I. (2005), "Consorcios locales”, en Muñoz Machado, S. (dir.), Diccionario de Derecho Administrativo, tomo I. A-G, lustel, Madrid, 2005, pág. 631;

NIETO GARRIDO, E. (1997), El Consorcio Administrativo, Barcelona: Cedecs.

- (2014), La Ley de racionalización y sostenibilidad de la Administración Local y los consorcios administrativos, en La reforma del Régimen Jurídico de la Administración Local: El nuevo marco regulatorio a la luz de la Ley de racionalización y sostenibilidad de la Administración Local (coord. por Juan Antonio Carrillo Donaire, Pilar Navarro Rodríguez) págs. 349-381.

NIETO GARRIDO, E. (2014), "La reforma de las entidades instrumentales por la Ley de Racionalización y Sostenibilidad de la Administración Local”, Revista Española de Derecho Administrativo, núm. 165, págs. $103-146$.

- (2016), "El nuevo marco jurídico del sector público. a propósito de la ley 40/2015, de 1 de octubre, de régimen jurídico del sector público", El Derecho (edición 9-XII-2016).

- (2016), "El consorcio administrativo", en Memorial: Estudios en homenaje al Profesor Santiago Muñoz Machado (coord. por José María Baño León), vol. 2, (tomo II), págs. 2.115-2.135.

PAZ-ARES, C. (1991), "Comentario de los arts. 1.665 al 1.707", en AA.VV, Comentarios del Código Civil (tomo II), Ministerio de Justicia.

REBOLLO PUIG, M. (1997), "Los consorcios entre entes locales como forma de cooperación", en FONT I LLOVET, T. (dir.), Anuario del Gobierno Local 1997, Diputación de Barcelona, Marcial Pons, Instituto de Derecho Público, Madrid.

RONCALÉS SAMANES, J. (2017), "Extinción y liquidación de comunidades de bienes y sociedades civiles", en AA.VV, Comunidades de Bienes y Sociedad Civil, Tirant lo Blanch, Valencia.

SÁNCHEZ BLANCO, A. (2006), Organización intermunicipal, lustel, Madrid, pág. 87.

TENA PIAZUELO, I. (2017), “Concepto, constitución y funcionamiento de la sociedad civil”, en AA.VV, Comunidad de bienes y sociedad civil, Tirant lo Blanch, Valencia. 
REALA. Nueva Época - N. ${ }^{7}$, mayo 2017 - ISSN: 1989-8975 - DOI: 10.24965/reala.v0i7.10423 - [Págs. 19-44]

La disolución y liquidación de los consorcios administrativos

Federico A. Castillo blanco

TORRES PEREA, J. M. (2002), La personalidad jurídica de la sociedad civil externa. Estudio comparativo de los ordenamientos español y alemán, Diario La Ley, núm. 5.539, Año XXIII, pág. 1.647, tomo 4, Editorial La Ley.

TOSCANO GIL, F. (2011), Los consorcios metropolitanos, Barcelona, Madrid, Fundación Democracia y Gobierno Local, IAAP.

- (2011), "La definición del Consorcio como entidad local en la legislación autonómica”, Cuadernos de Derecho Local, núm. 27, pág. 45.

- (2015), "El consorcio administrativo en la encrucijada", REALA (nueva época), núm. 3, enero-junio.

- (2017), "Los Consorcios Administrativos", en AA.VV, Tratado de Procedimiento Administrativo Común y régimen jurídico básico del sector público, Tirant lo Blanch, Valencia, 2017.

VALPUESTA GASTAMINZA, E. (2013), Comentarios a la Ley de Sociedades de Capital, Bosch, Barcelona.

VIGIL FERNÁNDEZ, C. (2015), "Las Ilamadas sociedades civiles con objeto mercantil y su régimen jurídico", Diario La Ley, núm. 8.551. Editorial La Ley. 